FEDERAL

RESERVE

BANK of

RESEARCH DIVISION

Working Paper Series

ST. LOUIS

\title{
Bankruptcy and Delinquency in a Model of Unsecured Debt
}

\author{
Kartik Athreya, \\ Juan M. Sánchez, \\ Xuan S. Tam \\ and \\ Eric R. Young
}

Working Paper 2012-042F

https://doi.org/10.20955/wp.2012.042

September 2016

FEDERAL RESERVE BANK OF ST. LOUIS

Research Division

P.O. Box 442

St. Louis, MO 63166

The views expressed are those of the individual authors and do not necessarily reflect official positions of the Federal Reserve Bank of St. Louis, the Federal Reserve System, or the Board of Governors.

Federal Reserve Bank of St. Louis Working Papers are preliminary materials circulated to stimulate discussion and critical comment. References in publications to Federal Reserve Bank of St. Louis Working Papers (other than an acknowledgment that the writer has had access to unpublished material) should be cleared with the author or authors. 


\title{
BANKRUPTCY AND DELINQUENCY IN A Model of Unsecured Debt
}

\author{
Kartik Athreya, Juan M. Sánchez, Xuan S. Tam and Eric R. Young*†
}

December 22, 2016

\begin{abstract}
This paper documents and interprets a fact central to the dynamics of informal consumer debt default: delinquency does not mean a persistent cessation of payment. In particular, we observe that for individuals 60 to 90 days late on payments, (i) $85 \%$ make payments during the next quarter to avoid getting into severe delinquency, and (ii) $40 \%$ reduce their debt (either because they made payments or received debt forgiveness). To understand these facts, we develop a theoretically and institutionally plausible model of debt delinquency and bankruptcy. Our model reproduces the dynamics of delinquency and suggests an interpretation of the data in which lenders frequently (in roughly $40 \%$ of cases) reset loan terms for delinquent borrowers, typically offering partial debt forgiveness, rather than a blanket imposition of the "penalty rates" most unsecured credit contracts specify.
\end{abstract}

JEL: E43, E44, G33.

Keywords: Consumer Debt, Bankruptcy, Default, Life cycle, Credit Card Delinquency

*Athreya: Federal Reserve Bank of Richmond, 701 East Byrd Street, Richmond, VA 23219; kartik.athreya@rich.frb.org. Sanchez: Research Division, Federal Reserve Bank of St. Louis, P.O. Box 442, St. Louis, MO 63166-0442; sanchez@stls.frb.org. Tam: Department of Economics and Finance, City University of Hong Kong, Kowloon Tong, Hong Kong SAR; xuanstam@cityu.edu.hk. Young: Department of Economics, University of Virginia, 224 Monroe Hall, Charlottesville, VA 22904; ey2d@virginia.edu.

${ }^{\dagger}$ We thank the Editors, Hal Cole and Dirk Krueger, for their detailed and clear guidance, and four anonymous reviewers, for their extremely detailed and perceptive comments. This feedback led to very significant revisions that we believe have greatly improved this paper. We also thank Lijun Zhu and Helu Jiang for their research assistance in the empirical part of the paper. 


\section{Introduction}

Consumer debt delinquency, whereby borrowers delay debt repayment to smooth consumption rather than invoke formal bankruptcy, is a quantitatively important phenomenon, with open-ended delinquency accounting for up to half of all unsecured consumer debt default. Delinquency, unlike bankruptcy, is informal default - it simply means non-payment of debt as initially promised. Interestingly, many borrowers classified as delinquent in a given quarter somehow recover or improve their credit status within one quarter. This finding, detailed below, emerges from recent credit bureau data. In particular, of individuals 60 or 90 days delinquent, (i) $85 \%$ avoid getting past 90 days delinquent one quarter later, and (ii) $40 \%$ reduce their debt, either because they made payments, received debt forgiveness, or both. The goal of this paper is to use data and theory to shed light on these two facts of informal default - especially to evaluate the extent to which quantitative models of consumer default can be useful to understand borrower-level short-term dynamics of delinquency.

The informality of delinquency complicates analysis and therefore the understanding of its consequences for borrowers. In particular, a feature of many unsecured lending contracts is a "penalty rate" on past-due debt. ${ }^{1}$ Under such terms, a missed payment leads to an automatic upward revision in the interest rate on existing debt. However, while most lenders might claim to impose such rates, the proportion of consumers who face such terms is not clear. Nor it is necessarily clear to consumers. Industry observers including consumer groups have noted, and pressed regulators to address, what may constitute a violation of the 2009 CARD Act, which places requirements on disclosure of credit terms. As a result, an open question is whether the data help us clearly discipline the interpretation of how borrowers

\footnotetext{
${ }^{1}$ Indeed, this is precisely how informal default was modeled in the important early work on consumer debt default of Livshits et al. (2007).
} 
are treated in delinquency.

Progress on this question first requires distilling data to capture key attributes. A primary contribution of our work is to collect for the first time, to our knowledge, all publicly available data on consumer debt delinquency, and then use these data to establish two stylized facts that describe individual-level dynamics associated with delinquency. Specifically, as noted above, we first show that delinquency does not mean a persistent cessation of payment. Second, we detail substantial dispersion in the change in the debt of delinquent borrowers. In addition, we assemble previously undocumented facts regarding heterogeneity in the use of delinquency (and bankruptcy) both by income group and across the lifecycle.

Once we establish the facts, we lay out a model of debt delinquency and bankruptcy that is theoretically and institutionally plausible - relative to current practice - and that nests a variety of specifications for what delinquency implies for borrowers and lenders. We then derive the predictions of two important polar cases of the model. The first case is where delinquency is met with by the imposition of an exogenous penalty rate that is applied to all delinquent borrowers. It is motivated by the "letter of the contract" which, in the unsecured credit market typically spells out a penalty rate for any late payment relative to the contract. The second case considered is one in which lenders choose the terms of delinquent borrowers ex-post (i.e., once they are in delinquency) to maximize the market value of delinquent debt. This case is motivated by both empirical and theoretical considerations. Empirically, we will show that the implicit terms experienced by delinquent borrowers frequently do not mimic the terms prescribed by ex-ante agreements to impose a penalty rate. Of course, almost by definition, such resetting of interest rates will not coincide except by accident with terms that borrowers and lenders might arrive at in a renegotiation. Theoretically, our approach is motivated by the simple fact that, absent commitment to imposing such rules, one would 
expect to observe such terms only when they prove ex-post valuable. Thus, a second natural case is one that does not impose anything purely "punitive" but instead allows lender and borrowers to always renegotiate loans.

Due to their institutional and theoretical plausibility, and for the light they shed on how delinquency affects borrowers, these two cases are each of independent interest. However, it is clearly important to use these cases to understand the extent to which the data are driven by either of these two models, first in their pure form and then when they are allowed to coexist. We therefore provide, along with the development of each of the two cases, a systematic assessment of the models' ability (and in places, the inability) to account for the facts we establish.

We show first that the pure penalty-rate specification, while superficially accurate for most of the credit card accounts given the standard description of lender behavior in the face of default, leads to only partially accurate implications. In particular, we show that this specification has reasonable implications for some of the characteristics of borrowers in delinquency, but it fails strongly to provide reasonable implications for the facts on both short-term borrowing dynamics following delinquency, and the evolution of credit terms in delinquency.

We then assess the specification that features optimal resetting of loan terms. In this case, upon the decision by the borrower to employ delinquency, lenders propose a revised debt obligation. We note that while in this case, lenders nominally propose the terms of renegotiation in a take-it-or-leave-it manner, their market power is still significantly limited. This is because borrowers always retain the option to refinance their debts in a competitive market as well as to file for bankruptcy. We show that while this model better matches the facts on borrower dynamics following a delinquency, it fails to fully reproduce the evolution 
of credit terms during delinquency. Thus, a conclusion of our model is that both types of consequences play a role in accounting for the facts. Furthermore, our approach allows the two to be tractably nested via the presence of a single parameter that specifies the probability that, in a given instance of delinquency, a penalty rate or optimal resetting will be applied. Our preferred model suggests a strictly positive probability (of roughly 40\%) of optimal resetting, with the remaining probability on a direct penalty rate.

Related literature. Our work is related to several recent papers on unsecured consumer credit markets. To begin, our approach is tied to Athreya et al. (2015), who study the implications of delinquency for the aggregate dynamics of consumer debt and default in the Great Recession, where the recession is represented by exogenous economy-wide changes in job-finding and job-destruction rates. This approach allows the use of a model of delinquency and bankruptcy to study the effects of labor market changes on aggregates. In contrast, the present paper does not focus on the time path of aggregates in a particular episode but instead on borrower-level debt dynamics and the implications the data have for the nature of borrower treatment in delinquency. We show that accounting for these additional facts disciplines how one interprets data on consumer delinquency relative to the interpretation in Athreya et al. (2015). Indeed, the data that we focus on here (borrower-level debt changes in delinquency and the transitions out of delinquency) are central for understanding what delinquency means to borrowers. Moreover, a main issue of concern here is the extent to which pure penalties and pure resetting describe the data; such an exercise is impossible in Athreya et al. (2015) as pure resetting of interest rates - which we show here to be partially inconsistent with the data - is mandated in that paper.

Our quantitative analysis is based on the specification of individual-level labor market 
outcomes in Low et al. (2010). There are two main characteristics of this specification that make it preferable for our purpose. First, given that delinquency is often a short-term phenomenon (our preferred measure of delinquency involves debt at least 90 days past due) and our goal is to study how individuals transition into and out of delinquency, we need a high-frequency (quarterly) income process that accurately reflects recent US data. Such a high-frequency income risk process cannot be recovered from estimations of, for example, annual income processes. Second, and importantly, this specification allows for short periods in which individuals receive no income, or become unemployed, which has been shown to significantly influence delinquency (Agarwal and Liu, 2003).

Our paper is related to recent work by Chatterjee (2010), Chatterjee and Gordon (2012) and Benjamin and Mateos-Planas (2014). Chatterjee (2010) and Livshits and Kovrijnykh (2015) are theoretical analyses of a lender's decision to pursue delinquent borrowers with heterogeneous and unobservable costs of filing bankruptcy; in our model, the cost of filing varies across borrowers (the consumption equivalent of the filing cost is larger for low-income filers) but is always observable. Moreover, for tractability, we represent the enforcement activity of the lender in a reduced-form manner. In contrast to Chatterjee and Gordon (2012), we model the process of loan modification explicitly by endogenizing the interest rate imposed on delinquent debt.

Our work is most closely related to Benjamin and Mateos-Planas (2014). These authors develop a quantitative equilibrium analysis of the implications of informal default along with formal bankruptcy. Their work stresses the potentially lengthy debtor-creditor renegotiation process, especially the aspect of "delay" on repayment, debt forgiveness, and welfare. Their innovative work presents a rich model of the individual balance sheet, which enables them to understand particular types of policies toward default that protect assets while provid- 
ing debt relief. They find that informal default plays a valuable role by giving borrowers the consumption-smoothing benefits of default with less damage than bankruptcy. ${ }^{2}$ Our approach places less emphasis on the protocol for renegotiation, the richness of individual balance sheets, and the implications of counterfactual policy experiments, and substantially greater emphasis on introducing a institutionally plausible model with quantitative aspects of individual labor-income risk and evaluating its predictions relative to a variety of microeconomic data.

Finally, our work is also related to the work of Herkenhoff and Ohanian (2012), who study the effect of mortgage default and modifications on labor markets. In their model, mortgages are perpetuities with fixed payments that can be delayed or modified. They find a strong connection between delayed payments and unemployment. Although the ability to delay credit payments also affect labor market choices in our analysis, our focus is on understanding what are the consequences of delinquency for credit cards borrowers.

\section{Debt, Delinquency, and Bankruptcy in the United States}

In this section, we detail institutional features of the unsecured consumer credit environment that pertain to default, both formally via bankruptcy and informally via delinquency; the data sources we use; and the stylized facts of both bankruptcy and delinquency that we derive from them.

\footnotetext{
${ }^{2}$ This smoothing occurs because informal default less severely hinders borrowers' ability to commit to (eventual) repayment and allows the deadweight losses of bankruptcy to be avoided. One interesting aspect of their work is that it stresses the differences between wealthy and non-wealthy debtors. Our model applies best to individuals with unsecured debt but no assets, a situation that describes well relatively younger individuals that, as we will show, constitute the bulk of defaulters.
} 


\subsection{Institutional Information about Unsecured Debt Markets}

Credit card contracts have long featured penalty rates for delayed repayment. The CARD Act of 2009 reaffirmed this option for lenders and allows such rates to be set after 60 days of delinquency. A body of evidence from industry practice that indicates three things related to how penalty rates are implemented. First, penalty rates on open ended loan contracts, such as credit cards, are set with substantial homogeneity. Information on penalty rates is gathered by the creditcards.com Penalty Rate Survey of 100 U.S. credit cards. This survey is a representative sample of cards from all major U.S. card issuers. In 2012, 91 percent of the issuer charged "penalty" interest rates, and the average interest rate was 28 percent. ${ }^{3}$ Figure 1 displays a typical credit card contract that specifies a penalty rate 5 percent higher for payments made 60 or more days late.

Second, lenders indicate that they are not always committed to imposing the penalty rate, either indefinitely, or at all. The 2014 CreditCards.com Penalty Rate Survey reports that 40 percent of respondents did not charge penalty rates. ${ }^{4}$ Pew-Charitable-Trusts (2010), for instance, argues that there exists "an emerging trend of credit card companies failing to disclose penalty interest rates in their online terms and conditions." The study reports that "at least 94 percent of bank cards and 46 percent of credit union cards came with interest rates that could go up as a penalty for late payments or other violations. But nearly half these warnings failed to inform the consumer of the actual penalty interest rate [italics added] or how high it could climb." An example of such a contract is displayed in Figure 2. ${ }^{5}$

\footnotetext{
${ }^{3}$ Information is gathered from the cards' terms and conditions documents, any publicly available cardholder agreements and phone calls to issuers.

${ }^{4}$ The ambiguity in post-delinquency lending terms is prevalent enough to concern regulators aiming to enforce "transparency" of lending terms. Notice that this behavior is consistent with a probabilistic application (from the borrower's point-of-view) of treatment practices following a delinquency.

${ }^{5}$ Similarly, according to Simon (2010), one of the largest credit card lenders in the U.S. has no announced penalty rate at all. The reason cited in Simon (2010) is "because we review accounts individually, we don't
} 
Figure 1: Credit Cards Contracts, Penalty Rate Example

\section{Discover Motiva Card}

\section{Overview | Rewards | Rates \& Disclosures \\ Important information about your Discover Motiva Card}

Know what to expect before you apply for a card by browsing the specific terms that may be offered to you based on your credit history.

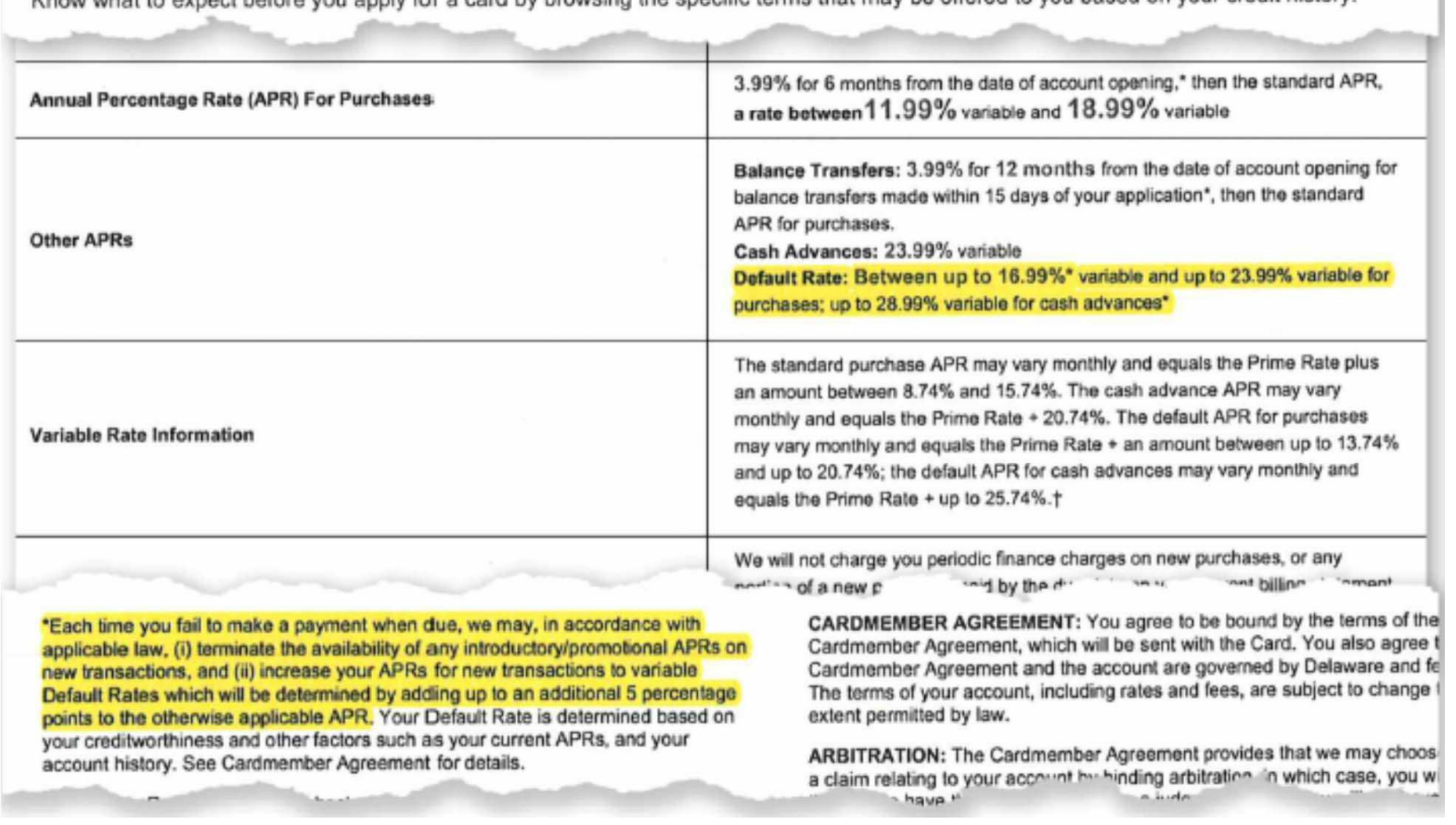

Source: Pew-Charitable-Trusts (2010). 
Third, and related to the first two points, even if the contract specifies a penalty rate, lenders routinely decline to commit to the implementation of penalty rates. ${ }^{6}$

While we cannot possible to directly link borrower-lender contract terms related to penalty rates to the data used, we read the practices described above as strongly suggestive of the relevance of studying the implications of penalty rates on allocations. Such a study would require a model such as ours, which, unlike almost all existing work on consumer debt default, features a default state distinct from bankruptcy. Moreover, the observation of industry practice also points to the potential fluidity of post-default terms of credit, something that suggests the salience of our investigation of the case in which lenders and borrowers are able to renegotiate terms.

To understand why credit card companies have incentives to renegotiate the preset penalty rate during delinquency, it is important to recall that typically, after a debtor has been delinquent for some time (between 120 and 180 days), the lender must, according to regulatory and general accounting standards, charge off (report as worthless) any loans. Such debts, as well as any others the initial lender identifies, may be sold to third-party collection agencies (who may in turn sell the debt to yet other buyers of distressed debt). The price of delinquent debt is among the only sources of data useful for estimating how much collectors expect to recover. A recent study by the Federal Trade Commission (FTC, 2013) contains information on such transactions. The FTC analyzed 3,399 portfolios of debts that were ultimately charged off. In these data, the mean price per dollar of "baseline debt" was 8 cents. Baseline debt is defined as credit card debt less than 3 years old, acquired from the original creditor, with a face value of less than $\$ 1,000$ and that has never been sent to a con-

have a set penalty rate ... [W]hen a consumer pays 60 days late or otherwise slips up, it triggers an account review that is used to determine whether to re-price the account."

${ }^{6}$ Typical contractual language specifies the lender's right to "amend those APRs." (Though the CARD Act forces advance warning of such changes) 
Figure 2: Credit Cards Contracts, Resetting Example

Terms and Conditions of BankAmericard Cash Rewards Visa__ close window
Signature Card

Print

\section{Details of Rate, Fee, and Other Cost Information}

As required by law, rates, fees, and other costs of the credit card offer are disclosed here. All account terms are governed by the Credit Card Agreement. Account and Agreement terms are not guaranteed for any period of time; all terms, including fees and the APRs for new transactions, may change in accordance with the Agreement and applicable law. We may change them based on information in your credit report, market conditions, business strategies, or for any reason. If this account becomes sixty days or more past due, we may amend the terms of the Agreement to increase all interest rates, including interest rates on existing promotional rate balances. You should thoroughly review all the materials in this package so that you are fully informed about your credit card loan.

\begin{tabular}{|l|l|}
\hline Interest Rates and Interest Charges \\
\hline $\begin{array}{l}\text { † Annual Percentage Rate } \\
\text { (APR) for Purchases }\end{array}$ & $\begin{array}{l}0 \% \text { Introductory APR for the first 7 or 10 statement Closing Dates } \\
\text { following the opening of your account, based on your creditworthiness. } \\
\text { See ' below for explanation. }\end{array}$ \\
& $\begin{array}{l}\text { After that, your APR will be 12.99\% to 20.99\%, based on your } \\
\text { creditworthiness when you open your account. This APR will vary with the } \\
\text { market based on the Prime Rate as set out in the Variable-Rate } \\
\text { Information section of your Agreement. }\end{array}$ \\
\hline APR for Balance Transfers & $\begin{array}{l}\text { 0\% Introductory APR for the first 7 or 10 statement Closing Dates } \\
\text { following the opening of your account for all Balance Transfers and Direct } \\
\text { Deposits, based on your creditworthiness. } \\
\text { See 1' and ' below for explanation. }\end{array}$ \\
\hline $\begin{array}{l}\text { After that, your APR for Balance Transfers and for any Direct Deposits } \\
\text { that were subject to the Introductory APR will be 12.99\% to 20.99\%, } \\
\text { based on your creditworthiness when you open your account. This APR } \\
\text { will vary with the market based on the Prime Rate. }\end{array}$ \\
\hline
\end{tabular}

Source: Pew-Charitable-Trusts (2010). 
tingency collector. This is consistent, under competitive conditions, with lenders essentially not expecting to recover the money.

The price of distressed debt depends, of course, on characteristics such as its size and age (e.g., days since the last missed payment). We find that debt that is either several years old or very high is more difficult, as encoded in secondary market prices, to collect on. ${ }^{7}$ For instance, for debts with face value between $\$ 5,000$ and $\$ 20,000$, the price is 2 cents cheaper than the unconditional mean of 6 cents per dollar of face value. As above, we interpret the fact that the price of debt is decreasing with the amount of debt as clearly suggesting that collection agencies do not necessarily expect to recover more from debtors owing larger amounts. At some point, how much can be recovered is determined by the debtor's characteristics, rather than the amount of debt they entered a given period with. This aspect will be a feature of our model, in which these terms will be determined endogenously.

Finally, to reflect the empirical regularity that while garnishment is allowed by law, it is limited by both U.S. federal and state law and is not common in practice, our models will not feature wage garnishment during delinquency. As a legal matter, garnishment is limited by the provisions of Title III of the Consumer Credit Protection Act. Lenders seeking to garnish wages or other forms of income (typically nonexistent) must obtain (i) approval from the relevant bankruptcy judge and (ii) written consent from debtors. Moreover, federal law places an upper limit on garnishment equal to 25 percent of income less deductions for other obligations, including taxes. As state and local taxes, Social Security taxes, alimony, child support, and student loan debts are all deducted before a debtor's income is eligible for garnishment, consumer lenders ultimately receive very low priority in garnishment. Moreover, six U.S. states completely rule out garnishment from the outset. In terms of direct evidence,

\footnotetext{
${ }^{7}$ An interesting case study of "hard to collect" debt can be found in the book Halpern (2014), which profiles debt collection activities in Buffalo, New York.
} 
ADP-Research-Institute (2014) found that only 7.2 percent of employees (from a sample of 13 million) had their wages garnished, and the majority of those garnishments were set to satisfy very specific forms of debt obligations (child support, student loans, or tax arrears) that our model is not concerned with. ${ }^{8}$ Unsurprisingly, therefore, debt collections for the types of consumer debt of interest to us here overwhelmingly rely on methods such as phone calls and letters that are not legally binding. We will therefore capture the totality of these costs with a simple utility cost experienced by all who invoke delinquency.

\subsection{Delinquency and Bankruptcy: Stylized Facts}

An important barrier to understanding consumer delinquency is that no single source contains all the data for which our model has implications. Additionally, in the case of renegotiation, there is little directly observable. To deal with these two constraints, we combine data from several sources: the Survey of Consumer Finances (henceforth, "SCF"); the Federal Reserve Bank of New York Consumer Credit Panel, which uses data from the credit bureau Equifax; the Board of Governors of the Federal Reserve System; the Administrative Office of the U.S. Courts; and the Panel Study of Income Dynamics (henceforth, "PSID"). We focus on three types of information: (i) aggregate data, (ii) cross-sectional data by age and income, and (iii) panel data on the dynamics of debt and delinquency.

Table 1 presents a list of key statistics for four different years, between 2004, 2007, 2010 and 2013, that we will employ to asses the roles played by bankruptcy and delinquency. We begin with the extensive margin of formal default: the personal bankruptcy rate, defined as the number of those filing for bankruptcy in a given year relative to the total number of individuals in the data. This rate is between 1 and 2 percent for each sample year. Since

\footnotetext{
${ }^{8}$ Earlier evidence on the rarity of successful garnishment can be found in Earl (1966) and Jacob (1969).
} 
the SCF asks about bankruptcy filings in the previous year, the highest rate corresponds to the recession year 2009, when it reached 1.76 percent, and the lowest rate 1.18 percent for the year 2006, the first year the so-called "BAPCPA" was implemented. 9

To measure the intensive margin of formal default (i.e., the magnitude of debt discharged), we measure bankrupt debt by computing the ratio of debt officially discharged in bankruptcy to the total amount of consumer debt outstanding. This ratio averages about 3 percent during the sample period.

Table 1: Aggregate statistics on debt, delinquency, and bankruptcy

\begin{tabular}{lllll}
\hline \hline & \multicolumn{4}{c}{ Data } \\
\cline { 5 - 5 } & 2004 & 2007 & 2010 & 2013 \\
\hline Bankruptcy rate & $1.47 \%$ & $1.18 \%$ & $1.76 \%$ & $1.30 \%$ \\
Bankrupt debt & $2.61 \%$ & $2.74 \%$ & $4.86 \%$ & $2.07 \%$ \\
Delinquency rate & $9.55 \%$ & $9.27 \%$ & $7.98 \%$ & $6.46 \%$ \\
Delinquent debt & $8.43 \%$ & $9.19 \%$ & $13.62 \%$ & $9.85 \%$ \\
Mean debt / Mean income & $1.44 \%$ & $1.64 \%$ & $5.00 \%$ & $4.57 \%$ \\
Mean interest rates & $12.73 \%$ & $13.72 \%$ & $14.48 \%$ & $14.78 \%$ \\
\hline \hline
\end{tabular}

Source: See Appendix.

While bankruptcy rates and debt are relatively straightforward to measure since they are contained in official U.S. court records, the same is not true for delinquent debt. We consider an account to be in delinquency if payment is 60 or more days past due. As with bankruptcy, there is an extensive margin and an intensive margin for delinquency. We similarly measure the delinquency rate by computing the number of individuals with at least one account in delinquency relative to the total number of individuals. This measure averaged about 8 percent over the sample period. Since the vast majority of U.S. borrowers have more than one

\footnotetext{
${ }^{9}$ The law dramatically increased the formal cost of filing. Since its implementation was announced well in advance of its effective date, it caused a large increase in bankruptcy filings in 2005, and a drop in filings in the following year. We abstract from these transitory fluctuations in filings, which are analyzed in Athreya et al. (2015).
} 
open unsecured credit account (Fulford, 2015), the delinquency rate is not an ideal measure of delinquency. The inability to speak directly to these data also reflects a limitation of our model: Ideally, one would like to allow for multiple contracts. However, the substantial complications that such a model would require would compromise tractability and make our model depart more from existing work on defaultable consumer debt including the important benchmark environments of Chatterjee et al. (2007) and Livshits et al. (2007). To capture actual delinquent debt, we use the fraction of credit card debt that is currently delinquent, which averaged 10 percent during the sample period.

The last two statistics in Table 1 show the extent of borrowing, along with a measure of the relevant consumer interest rate. There are two standard approaches to defining debt in research that employs, as we do, a single-asset model of consumer debt and default. The first is to define debt as gross unsecured debt, and the second is to define it as the maximum of two objects: negative net worth and zero. In this paper, we will employ the latter, and so follow, among others, the important early work of Chatterjee et al. (2007). The extent to which this measure satisfactorily captures the total defaultable debt that a borrower holds depends on the extent to which those in default are also who those who have negative net worth. Using data from official Court records (from the Administrative Office of US Courts) for 2007 Chapter 7 bankruptcy filers, we are able to verify that almost all bankruptcy filers (88 percent) actually had negative net worth. ${ }^{10}$. This suggests that net worth is useful for capturing incentives to file for bankruptcy and to default more generally. Unfortunately, data limitations prevent performing the same calculation for delinquency. The best available data source for delinquency, the NY Fed Credit Panel Equifax, does not have information

\footnotetext{
${ }^{10}$ Moreover, if we subtract home equity from net worth to construct "liquid" net worth, the share of filers with negative liquid net worth rises to 98 percent
} 
for borrower net worth. ${ }^{11}$ Given the close relationship between delinquency and bankruptcy emphasized in this paper, we expect that nearly all the households 90 or more days late in credit card payments have negative net worth, hence allowing our approach to reasonably capture default incentives. ${ }^{12}$ Measured this way, average debt relative to average income was 3 percent during the sample period and, like the other measures, increases over time. Finally, the yearly mean interest rate on credit cards is relatively constant at approximately 13.5 percent.

Figure 3 shows the distribution of bankruptcies over the lifecycle (left panel) and income quartiles (right panel). The data for bankruptcy by age come from the PSID 2007, while the data across income levels comes from U.S. courts records for 2008. The bankruptcy rate is decreasing in both age and income. For instance, more than 50 percent of the bankruptcies were filed by individuals 25 to 34 years old, with 75 percent in the first income quartile. ${ }^{13}$

Similarly, Figure 4 shows the distribution of debt in delinquency over the life-cycle and

\footnotetext{
${ }^{11}$ Data on delinquency from the SCF is not ideal because the SCF does not allow us to distinguish the types of household debts; rather, it asks about all types of debts, not only credit card. If we accept these limitations and proceed, we find from those that answer in the SCF that of the households who respond as delinquentas measured by missing payments for two months, we find that 33 percent had negative net worth, 41 percent had negative "liquid" net worth, and 44 percent have credit card debt. Clearly, therefore, this question captures much more than delinquency in credit card debt.

${ }^{12}$ While we follow one of the standard practices in our definition of borrowing, this definition involves a judgment call. Of course, there is a trade-off between using the standard definition instead of defining debt as the gross amount of the most obvious form of unsecured debt: credit card debt. Credit card debt also has the advantage of more closely approximating the amount of debt that can be discharged in bankruptcy. Nonetheless, for our goals, net worth is a better measure simply because it more closely matches the object that the model has implications for. Our model features a single asset, and it is trivially true that any model with one asset and a life-cycle profile of income has no chance of replicating the much richer balance sheet to which individuals have access in reality. In any single-asset model, what happens instead is that younger and poorer individuals hold debt, while older and richer individuals hold only assets in preparation for retirement. Moreover, a drawback of using gross credit card debt to think about the consumption-smoothing implications of default is that many older and richer individuals hold this type of debt together with other financial assets for reasons that the literature has struggled to fully understand (see, e.g., Lehnert and Maki, 2002; Telyukova and Wright, 2008).

${ }^{13} \mathrm{We}$ construct four income and age groups because for some of the surveys we use (e.g. SCF and PSID) the number of observations in default is very small.
} 
Figure 3: Bankruptcies age and income quartile
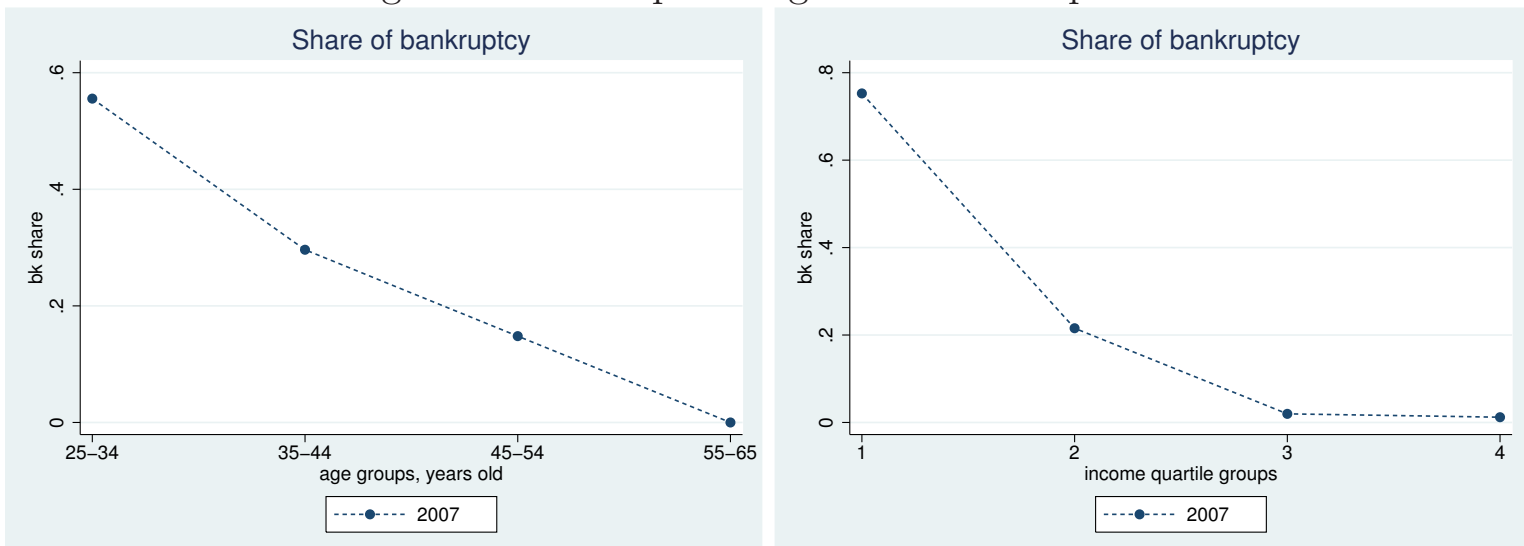

Source: See Appendix.

across income groups for the same years. In both cases the patterns have remained fairly stable over time. The left panel shows that individuals 35 to 54 years old hold most - about 60 percent - of delinquent debt. The right panel shows that most delinquent debt-between 40 and 60 percent - is held by individuals in the poorest income quartile.

Figure 4: Delinquent debt by age and income quartile
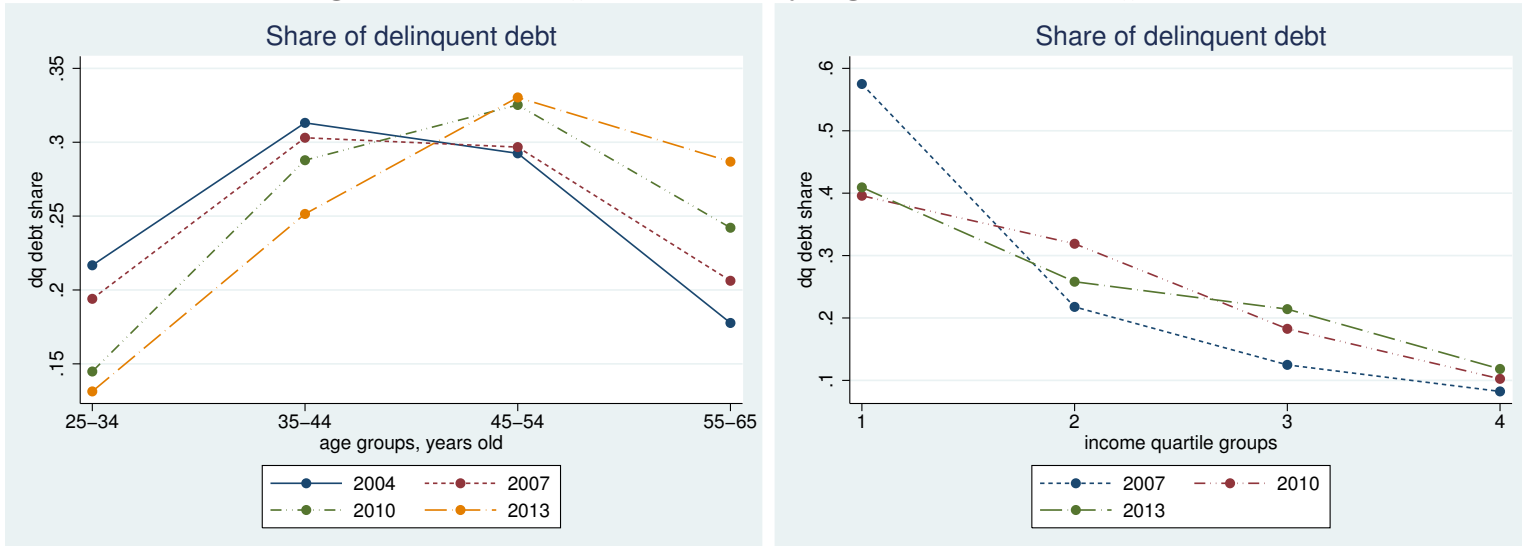

Source: See Appendix.

Figure 5 shows overall unsecured debt, measured as previously defined, by age and income. As clearly seen, the bulk of debt is held by individuals younger than 45 years old and, 
alternatively, by those in the bottom two income quartiles.

Figure 5: Debt by age and income quartile
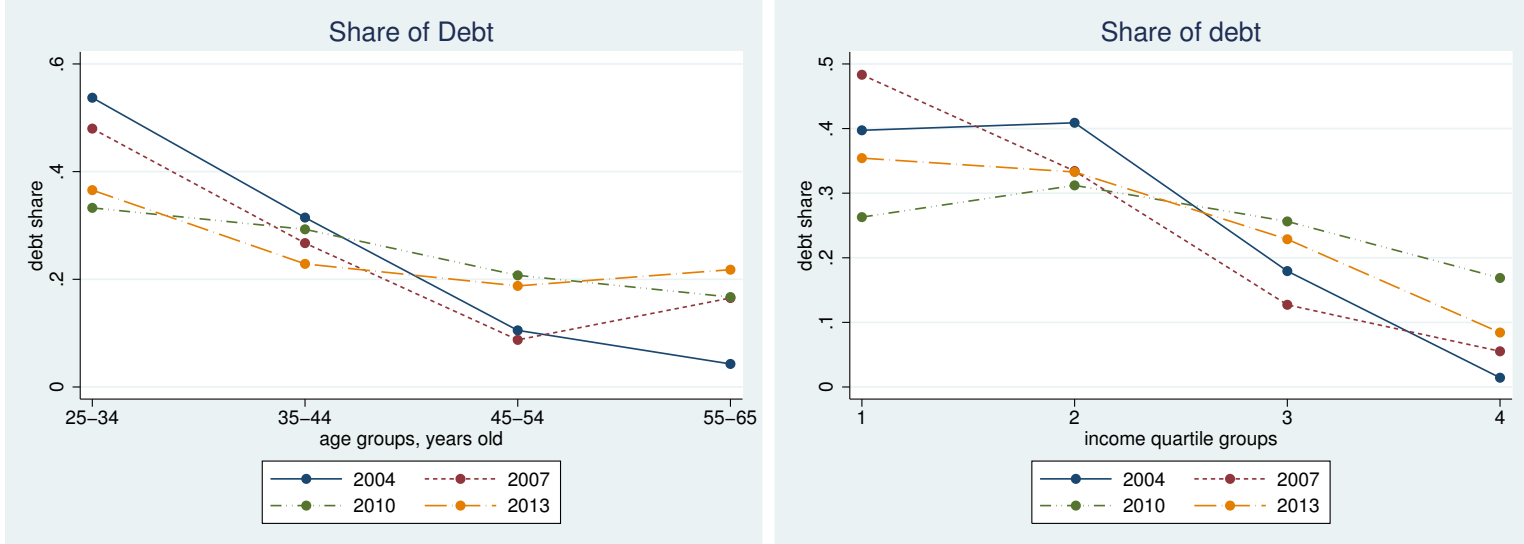

Source: See Appendix.

Thus far, we have presented cross-sectional moments. However, our focus in this paper is primarily on facts regarding borrower-level debt and repayment dynamics, and the interpretation that quantitative theory implies for how delinquency affects borrowers. Therefore, to examine the empirical dimensions of these dynamics, we turn now to a third source of data: panel data from the Federal Reserve Bank of New York Consumer Credit Panel/Equifax. The results in Table 2 display the dynamics of delinquency. In particular, the first three rows show the probability that an individual current on payments in the present quarter will be in delinquency, bankruptcy, or current in the following quarter. The results show clearly that "healthy" credit status is a persistent phenomenon. Individuals in good financial condition (current on payments) are very likely (more than 98 percent) to stay that way at least one-quarter ahead. This probability is, moreover, stable over time, at least in the decade from 2004 through 2013. Additionally, the second and third rows of Table 2 show that when borrowers exit "current" status, they do so predominantly via delinquency; it is the first stop on route to default. Specifically, notice that on average, the probability of transitioning 
Table 2: Transition probabilities

\begin{tabular}{lcccc}
\hline \hline Probabilities: & 2004 & 2007 & 2010 & 2013 \\
\hline Current at $t$ \& current at $t+1$ & 98.70 & 98.57 & 98.82 & 99.19 \\
Current at $t \&$ DQ at $t+1$ & 1.18 & 1.38 & 1.12 & 0.77 \\
Current at $t$ \& BK at $t+1$ & 0.12 & 0.05 & 0.06 & 0.04 \\
\hline DQ1 at $t$ \& making payments at $t+1$ & 84.44 & 85.00 & 88.23 & 84.88 \\
DQ1 at $t$ \& making no payments at $t+1$ & 13.09 & 14.04 & 19.90 & 14.12 \\
DQ1 at $t$ \& file BK at $t+1$ & 2.47 & 0.96 & 1.97 & 1.00 \\
\hline \hline
\end{tabular}

Source: See Appendix.

from current to delinquent status is approximately 1 percent, while the probability of moving from current to bankrupt status is less than one-tenth as large, at less than 0.1 percent.

The last three rows show the probabilities that an individual currently 60 or 90 days delinquent (DQ1) in the present quarter will resume payments, make no payments, or be in bankruptcy in the following quarter. A key finding here is that the cessation of payments is not highly persistent. We see that most - about 85 percent - of the individuals 60 or 90 days delinquent in a given quarter make payments during the next quarter to avoid further damage to their credit status. Also note that the transition from delinquency (60 or 90 days past due) to bankruptcy is much higher than the unconditional bankruptcy rate. In sum, while delinquency is the entry point to default, it is clearly informative for the likelihood of bankruptcy and further delinquency.

Finally, to understand what happens to delinquent debt from one quarter to the next, we compute the change in debt from $t$ to $t+1$ for debt that is delinquent in period $t$. This is an interesting dimension of debt dynamics that will be key to identify among the alternative models. Indeed, in our models, this change in debt will be driven principally by what occurs in delinquency. For instance, in the "penalty rate" model, all borrowers will have a change equal to the value of the penalty rate. Figure 6 shows the distribution of the change in debt 
Figure 6: Changes in debt for Individuals in Delinquency

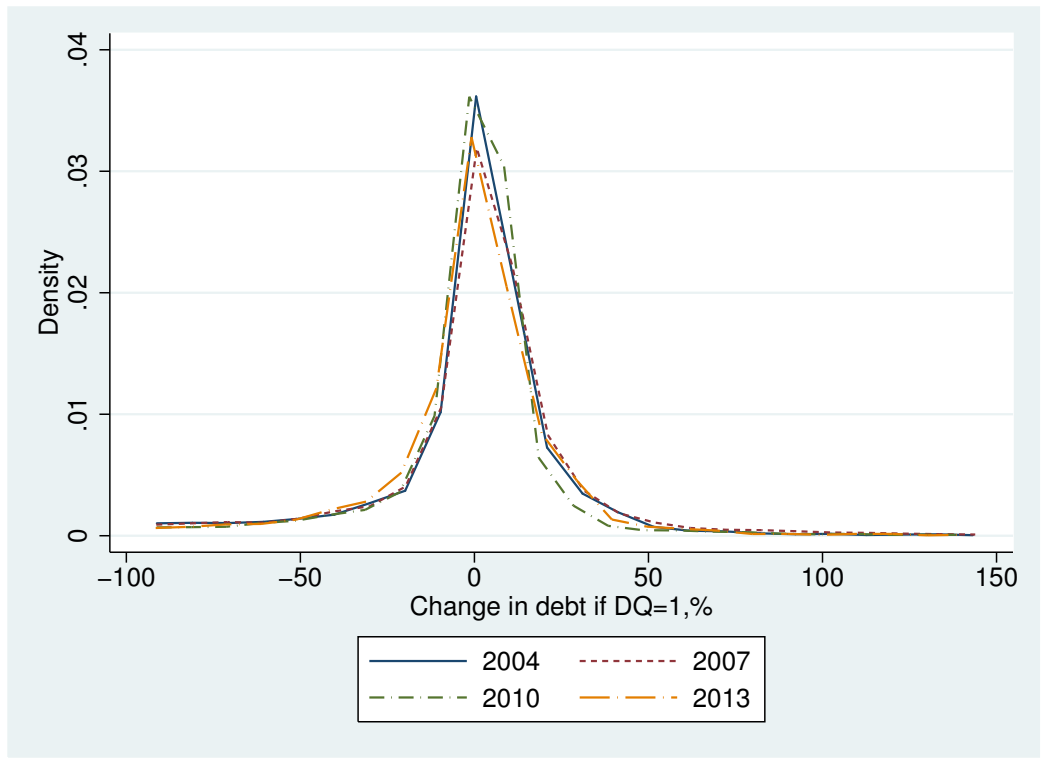

Source: See Appendix.

between period $t$ and $t+1$ for individuals in delinquency in period $t$. The mass to the left of zero, which is about 40 percent, represents the share of individuals who were in delinquency in period $t$ that experienced a reduction in debt. This a clear indication of the empirical failure of models that would restrict all delinquent debt to accrue interest at an exogenous penalty rate. Moreover, it is important to highlight that although debt increased for the majority of the individuals, the rate at which it grows varies widely across individuals. This heterogeneity is, again, difficult to reconcile with the idea that individuals in delinquency are charged the same fixed penalty rate. By contrast, these findings are more in line with the idea that individuals get a settlement related to a measure of their repayment capacity, precisely the feature present in our models with resetting of credit terms during delinquency.

Having provided as complete a record of data available on debt, delinquency, income, and demographics as the data allow, we now turn to the model we use to interpret and account 
for these facts.

\section{Model}

The framework considered here is a life-cycle model of consumption and savings extended to incorporate consumer credit and two types of default: delinquency and bankruptcy, where agents face wage and employment risk and have access to a social safety net (as in Low et al., 2010). Our model of the labor market largely follows that in Low et al. (2010) because of that model's richness at representing high-frequency risks and opportunities for earnings. However, as we note below, we abstract from one aspect of their model-disability risk and insurance - as it turns out to simplify exposition without compromising any of our main results.

\subsection{Wages and Labor Market Risk}

Time is discrete, and a model period corresponds to one quarter. Agents enter the labor

market at age $\underline{t}$, retire at age $\bar{t}$, and die at age $\overline{\bar{t}}$. All agents face earnings risk. One source is productivity risk, which we represent with a process that depends on a deterministic component, $x_{t}^{e}$, which varies over the life cycle and depends on education, and a shock, $n$, which follows a random walk, whereby $n_{t}=n_{t-1}+\zeta_{t}$. These aspects of individual productivity are innate. A second source of risk arises from the structure of labor markets: Labor is allocated through random matching between individuals and firms, and the overall productivity of an agent also depends on the quality of the agent's match. Specifically, once matched, a worker-firm match yields productivity for a particular job that depends not only on $x_{t}^{e}$ and $n_{t}$ but also on a match-specific component, $m$, that changes only when the worker 
changes firms. ${ }^{14}$ New draws of match quality come from a normal distribution with mean 0 and variance $\sigma_{m, e}^{2}$. Thus, an agent with education $e$, current productivity $n$, and a match quality $m$, faces a wage given by

$$
w_{t}^{e}(n, m)=\exp \left(x_{t}^{e}+n_{t}+m_{t}\right) .
$$

Matched agents have the option, but not the obligation, to work, and therefore decide whether to accept any work opportunity offered. If they accept, they supply a fixed amount, $H$, of time. This variable captures the difficulty of varying work hours at the high frequencies addressed by our model. The reason not all matched workers work is that working creates disutility and carries a fixed cost, $F^{e}$, that captures, e.g., the need to commute.

All agents are subject to a proportional tax on all earnings $\tau$ by a government that uses the proceeds to finance social programs (detailed further below). Thus, the disposable earnings of a worker electing to work are

$$
y_{t}^{e}(n, m)=w_{t}^{e}(n, m) H(1-\tau)-F^{e} .
$$

\subsubsection{Search and Matching}

As noted, agents and firms must match to produce, and both matched and unmatched workers may receive work opportunities in any given period. From the agent's perspective, job offers arrive with probability $\lambda^{e, J}$ if the individual is currently employed ( $J$ is a mnemonic for "job") and $\lambda^{e, U}$ if they are unemployed (for which we use the mnemonic $U$ ). As before, the superscript $e$ denotes the dependence of these probabilities on education. Once a job offer

\footnotetext{
${ }^{14}$ Note that firms do not differ in their productivity. Rather, workers at any time belong to a particular match that determines (in part) their productivity.
} 
arrives, the individual draws the quality of match, $m$. At this point, an agent knows their wage in the period and so is fully informed with respect to accepting or rejecting the offer. For employed workers, this choice represents a decision of whether to switch jobs. Additionally, employed workers can quit. They may quit to pursue other employment opportunities or become unemployed. Lastly, all worker-firm matches are subject to exogenous destruction at a rate that varies with educational attainment, $\delta^{e}$.

The structure we use is meant to help us capture an extremely rich array of empirically relevant labor market incentives and constraints that affect individuals at high frequencies. Such capturing is important given that delinquency decisions hinge on the availability of short-term debt relief through a delay in debt repayment or social insurance. Delays in debt repayment are, in turn, useful precisely because of constraints that apply to individuals in the very short run, including most obviously those arising from the failure to secure work.

\subsection{Social Safety Net}

Our goal of understanding individual debt repayment decisions in the face of unfolding wage and employment risk requires us to capture the presence of any state-contingent transfers the individual is entitled to receive. For most individuals, the most important such asset is the social safety net provided by the government. Turning first to unemployment, there is an unemployment insurance (UI) system that partially insures workers against the risk of unemployment. Individuals receive unemployment payments during the first period of unemployment, but to reflect U.S. practice, only those who do not lose a job by quitting their jobs are eligible for benefits. ${ }^{15}$ Eligibility for UI is denoted by the indicator $u \in\{0,1\}$. The UI system sets a replacement ratio $\vartheta$ relative to earnings $y$, and caps total benefits at a

\footnotetext{
${ }^{15}$ We abstract from the moral hazard problem associated with misclassifying quitters as having been laid off.
} 
maximum benefit $\Lambda$. Thus, benefits are given by the function

$$
u i_{t}^{e}(n)=\min \left\{y_{t}^{e}(n, \bar{m}) \vartheta, \Lambda\right\},
$$

where $\bar{m}$ is the median value of match quality $m$ which, for parsimony, we use to determine the unemployment insurance payment for all unemployed workers.

A more general array of safety net programs is also in place. First, low-income individuals are eligible to receive food stamps, modeled simply as an increment of income up to $\Gamma$. These transfers are represented by a function $T(\cdot)$, of current income $y$, specified as follows:

$$
T(y)= \begin{cases}\Gamma-0.3 \times y & \text { if } y \leq \underline{Y} \\ 0 & \text { otherwise }\end{cases}
$$

Second, retired individuals receive benefits represented by the function $g$ of their last realization of labor income. The formula used to determine the payment in retirement is

$$
g(x)= \begin{cases}0.9 \times x & \text { if } x \leq a_{1}, \\ 0.9 \times a_{1}+0.32 \times\left(x-a_{1}\right) & \text { if } a_{1}<x \leq a_{2}, \\ 0.9 \times a_{1}+0.32 \times\left(a_{2}-a_{1}\right)+0.15 \times\left(x-a_{2}\right) & \text { if } a_{2}<x \leq a_{3}, \\ 0.9 \times a_{1}+0.32 \times\left(a_{2}-a_{1}\right)+0.15 \times\left(a_{3}-a_{2}\right) & \text { if } x>a_{3},\end{cases}
$$

where $x$ is previous-period income.

Although Low et al. (2010) also include the disability insurance option for workers with low productivity, its inclusion has no significant effect on any of our variables of interest, so we exclude it from our model to simplify the exposition. 


\subsection{Credit Markets}

At any age $t$, an individual wishing to borrow may issue one-period debt with face value $b$. As is standard, debt is priced as if $b$ were issued to a single lender who must compete with a large number of lenders. As a result, individual debt issuances will earn zero expected profits. This approach is standard (e.g., Chatterjee et al., 2007; Livshits et al., 2007). Lenders, moreover, are perfectly diversified across borrowers in any given current state. This diversification is relevant since borrowers have the option to default. The ability to avoid full repayment when it is due also implies that the individual's debt issued during the current period, $b$, will be discounted relative to its face value. The discount will be encapsulated by the price function $q: b \rightarrow[0,1]$ that maps any chosen individual debt level to a discount factor between 0 and 1. Thus, a borrower issuing an obligation with face value $b$, whose current state (and, hence, default incentives) leads to a price of $q$, will receive $q b$ units of the consumption good in the current period and face the obligation to repay $b$ units tomorrow. Note however that the price of a borrower's debt will not depend on their labor market decision in a given period.

In the period following a given debt issuance, borrowers can do one of three things: (i) repay debts as promised; (ii) file for bankruptcy protection, which immediately relieves them of all obligations to repay their debts; or (iii) simply fail to repay their debts as promised, hereafter referred to as delinquency.

Both bankruptcy and delinquency carry costs. But while bankruptcy imposes financial costs and direct utility costs, it also completely removes the individual's debt obligations (our model captures U.S. Chapter 7 bankruptcy, which is the dominant route; see, e.g., Sullivan et al., 2000). By contrast, delinquency does not automatically remove debt and exposes the borrower to potentially higher future debt obligations. Thus, the central difference between bankruptcy and delinquency is that, after delinquency, the borrower still owes a debt to the 
lender. Below we consider three alternative ways of determining the value of debt in the period after delinquency.

An important aspect of our model is that it allows us to endogenize the interest rate on delinquent accounts by allowing lenders to mark up or charge off delinquent accounts. Moreover, lenders ability to mark up interest rates on delinquent loans is limited by the individual's option to declare bankruptcy in the future.

Before proceeding, note that delinquency costs are difficult, if not impossible, to directly observe. Given the prevalence of legislation that restricts lenders from imposing nonpecuniary costs on borrowers, it is clear that these costs exist. ${ }^{16}$ Therefore, we consider two possibilities; one where all delinquent debt is assigned a fixed "penalty rate" in line with credit card contractual terms, and one where the nonpecuniary cost of default is a fixed number that is independent of debt. In the second specification, and in regard to how lenders set interest rates for delinquent borrowers, our model most resembles that of Kovrijnykh and Szentes (2007). That is, if a borrower chooses delinquency, the incumbent lender immediately resets the value of the principal owed to maximize the expected present value of the loan conditional on the borrower's current state; that is, interest rates in delinquency satisfy only what is ex-post optimal for lenders - though lender power is limited by the availability of formal bankruptcy as an outside option for the borrower.

\footnotetext{
${ }^{16}$ The Fair Debt Collection Practices Act of 1977 restricts a number of activities that lenders could use to impose costs on delinquent borrowers, such as phone calls and letters. For example, lenders cannot phone at unreasonable times, cannot call relatives or the workplace, and cannot make statements about consequences of non-repayment that are false or illegal.
} 


\subsection{Preferences}

Turning next to households, the within-period utility function is

$$
v(c, p)=\frac{\left(c \exp \left(\varphi^{e} p\right)\right)^{1-\sigma}}{1-\sigma}
$$

where $\sigma>1$ is the coefficient of relative risk aversion and $\varphi^{e}<0$ governs the disutility of supplying labor. ${ }^{17}$ The indicator variable $p$ captures working status, where $p=1$ represents working persons, while $p=0$ represents nonworkers. In addition, the nonpecuniary costs of both formal and informal default will be represented as additive costs (i.e., total within period utility is the sum of the flow arising from optimal consumption and labor effort and the negative flow consequences of any applicable nonpecuniary costs of default). Finally, agents discount factor is $\beta \in(0,1)$.

\subsection{Recursive Formulation of the Household Problems}

We now describe the individual's problem recursively. It is easiest to proceed by dividing individuals first into two main groups: (i) those who are working age and (ii) those who are retired. The group of working-age individuals can, in turn, be divided into those who (i) have a job offer and (ii) those who do not have a job offer.

To set notation, let $\kappa \in\{U, O, R\}$ denote the current labor market status of an individual, where $\kappa=U$ means the individual is currently unemployed, $\kappa=O$ means the individual has a job offer, and $\kappa=R$ means the individual is retired.

\footnotetext{
${ }^{17}$ Notice that values in the interval $0<\sigma<1$ imply implausible behavior, as the marginal utility of consumption would be lower when working rather than when taking leisure. We thank an anonymous referee for drawing our attention to this fact - a point also made in Low et al. (2010). As it turns out, our baseline calibration will fix $\sigma=2$, which removes the possibility of this strange implication. Also, notice that this specification of disutility is akin to the agent losing a fraction of consumption - or limiting the "bang for buck" arising from any given consumption level $c$.
} 
Next, we describe the Bellman equations for the working-age population, for those with $t<\bar{t}-1$, and then for those in retirement, those with $t>\bar{t}-1$. If $t=\bar{t}-1$, the individual is currently in the labor force but will be retired in the next period; the value function thus differs from the other two cases but still remains very simple. The problem in the last period of life is also different, since there is no value associated with the future, and is omitted for brevity.

\subsubsection{Individuals without a Job Offer}

We begin with a person who has no job offer in the current period and only a creditmarket related decision: If indebted, the individual must choose whether to use bankruptcy, delinquency, or full debt repayment (solvency), or instead choose how much to save. We express the value of each of the credit market option as follows.

Bankruptcy. Among those without a job offer (labor market status $U$ ), education $e$, current productivity $n$, and UI eligibility status $u \in\{0,1\}$, the value of filing for bankruptcy is given by

$$
B_{t}^{e, U}(n ; u)=v(c, 0)-\psi_{B}+\beta\left(1-\lambda^{e, U}\right) \mathbb{E}_{n^{\prime}}\left[P_{t+1}^{e, U}\left(0, n^{\prime} ; 0\right)\right]+\beta \lambda^{e, U} \mathbb{E}_{n^{\prime}, m^{\prime}}\left[P_{t+1}^{e, O}\left(0, n^{\prime}, m^{\prime}\right)\right],
$$

subject to $c=u i_{t}^{e}(n) u+T(0)-\Delta_{0}$, for $t \in[\underline{t}, \bar{t}-2]$.

Initially, the individual's utility is given by $v(c, 0)$, as they are not working in the current period. Notice (from the budget constraint) that because borrowers would have their debt fully removed by bankruptcy and may not save or borrow in the current period, there is essentially no optimization required conditional on the choice of bankruptcy. Bankruptcy inflicts (i) a cost $\psi_{B}$ directly to utility and (ii) a resource cost of filing equal to $\Delta_{0}$ (as seen 
in the budget constraint).

For current bankruptcy filers, the continuation value is simply the value along the repayment branch, denoted $P(\cdot)$ (and detailed further below), since the agent will have no debt, implying that solvency will dominate delinquency and bankruptcy. Next period, if the individual fails to receive a job offer, which occurs with probability $1-\lambda^{e, U}$, she will again prefer repayment and obtain value $P_{t+1}^{e, U}\left(0, n^{\prime} ; 0\right)$, where $n^{\prime}$ is next-period productivity and $u=0$ since the individual will, at that point, have been unemployed for more than one quarter, which exhausts their eligibility for UI. The final term in the value function, $P^{e, O}(\cdot)$, refers to those agents (with education $e$ ) who enter the next period with a job offer.

Delinquency. The lifetime value of opting for delinquency is very similar to that derived from bankruptcy. The key differences are as follows: First, the resource cost of filing for bankruptcy is absent in case of delinquency. Second, the utility cost, $\psi_{D}$, is allowed to differ from that derived from bankruptcy. Third, the borrower is not free from debt obligations, which evolve according to a law of motion (detailed further below) for their immediate postdelinquency debt obligation, $h^{\prime}$. Thus, the lifetime value of delinquency is

$$
\begin{aligned}
D_{t}^{e, U}(b, n ; u) & =v(c, 0)-\psi_{D}+ \\
& \beta\left(1-\lambda^{e, U}\right) \mathbb{E}_{n^{\prime}}\left[\max \left\{B_{t+1}^{e, U}\left(n^{\prime} ; 0\right), D_{t+1}^{e, U}\left(b, n^{\prime} ; 0\right), P_{t+1}^{e, U}\left(h^{\prime}, n^{\prime} ; 0\right)\right\}\right]+ \\
& \beta \lambda^{e, U} \mathbb{E}_{n^{\prime}, m^{\prime}}\left[\max \left\{B_{t+1}^{e, O}\left(n^{\prime}, m^{\prime}\right), D_{t+1}^{e, O}\left(b, n^{\prime}, m^{\prime}\right), P_{t+1}^{e, O}\left(h^{\prime}, n^{\prime}, m^{\prime}\right)\right\}\right],
\end{aligned}
$$

subject to $c=u i_{t}^{e}(n) u+T(0)$,

$$
h^{\prime}=\gamma_{t}^{e, U}(b, n ; u, 0), \text { for } t \in[\underline{t}, \bar{t}-2] .
$$


The expectation term shows that next period, the individual will have a nontrivial choice between bankruptcy, continued delinquency, and repayment, respectively. The two continuation terms reflect agent optimization with respect to repayment options along the paths in which the individual fails and succeeds, respectively, in obtaining a work opportunity.

Repayment. Lastly, consider the problem of an individual without a job offer who elects to repay debts as initially promised. The resulting Bellman equations, $P(\cdot)$, are very similar; the primary difference is that this individual is eligible to borrow in the current period:

$$
P_{t}^{e, U}(b, n ; u)=\max _{b^{\prime}}\left\{\begin{array}{c}
v(c, 0)+ \\
\lambda^{e, U} \beta \mathbb{E}_{n^{\prime}, m^{\prime}}\left[\max \left\{B_{t+1}^{e, O}\left(n^{\prime}, m^{\prime}\right), D_{t+1}^{e, O}\left(b^{\prime}, n^{\prime}, m^{\prime}\right), P_{t+1}^{e, O}\left(b^{\prime}, n^{\prime}, m^{\prime}\right)\right\}\right]+ \\
\beta\left(1-\lambda^{e, U}\right) \mathbb{E}_{n^{\prime}}\left[\max \left\{B_{t+1}^{e, U}\left(n^{\prime} ; 0\right), D_{t+1}^{e, U}\left(b^{\prime}, n^{\prime} ; 0\right), P_{t+1}^{e, U}\left(b^{\prime}, n^{\prime} ; 0\right)\right\}\right]
\end{array}\right\},
$$

subject to $c=u i_{t}^{e}(n) u+T(0)+b-q_{t}^{e, U}\left(b^{\prime}, n ; 0\right) b^{\prime}$, for $t \in[\underline{t}, \bar{t}-2]$.

Given that this individual has elected to repay, she has access to the credit market in the current period and face loan pricing terms $q_{t}(\cdot)$ (detailed further below). Notice that if $b^{\prime}>0$, the question of bankruptcy or delinquency one period hence does not arise and the continuation value collapses to $P(\cdot)$.

\subsubsection{Individuals with a Job Offer}

Turning now to those with a job offer in the current period, we see that, with debt $b$, they have several choices. In terms of debt repayment, borrowers can, as always, choose bankruptcy, delinquency, or solvency. In this case, the primary additional choice is whether to accept the job offer. 
Bankruptcy. The bankruptcy decision, if made optimally, yields value

$$
B_{t}^{e, O}(n, m)=\max \left\{B_{t}^{e, U}(n ; 0) ; B_{t}^{e, J}(n, m)\right\}
$$

The first term represents the value of declaring bankruptcy and rejecting the offer and the second the value arising from accepting. The latter is given by

$$
\begin{aligned}
& B_{t}^{e, J}(n, m)=v(c, 1)-\psi_{B}+\beta \delta^{e} \mathbb{E}_{n^{\prime}}\left[P_{t+1}^{e, U}\left(0, n^{\prime} ; 1\right)\right]+ \\
& \quad \beta\left(1-\delta^{e}\right)\left(\left(1-\lambda^{e, J}\right) \mathbb{E}_{n^{\prime}}\left[P_{t+1}^{e, O}\left(0, n^{\prime}, m\right)\right]+\lambda^{e, J} \mathbb{E}_{n^{\prime}, m^{\prime}}\left[P_{t+1}^{e, O}\left(0, n^{\prime}, m^{*}\right)\right]\right)
\end{aligned}
$$

subject to $c=y_{t}^{e}(n, m)+T\left(y_{t}^{e}(n, m)\right)-\Delta_{1}$,

$$
m^{*}=\max \left\{m^{\prime}, m\right\} \text {, for } t \in[\underline{t}, \bar{t}-2] .
$$

The preceding circumstance arises as follows. If an individual with a job $(J)$ files for bankruptcy, they derive utility $v(c, 1)$ from consumption in the current period, suffer the nonpecuniary cost $\psi_{B}$, and pay $\Delta_{1}$, which is the relevant cost of filing for bankruptcy since this agent is employed. In the following period, the individual may see her employment match destroyed, something that occurs with probability $\delta^{e}$, which yields the expected value $\mathbb{E}_{n^{\prime}} P_{t+1}^{e, U}\left(0, n^{\prime} ; 1\right)$. With probability $\left(1-\delta^{e}\right)$, she enters the following period with the current match intact. Recall that the individual may receive a job offer even while employed. If the individual does not receive a new offer, she realizes value $\mathbb{E}_{n^{\prime}} P_{t+1}^{e, O}\left(0, n^{\prime}, m\right)$, but if she draws a new job offer, she will choose the better of the two options available, yielding the expected value of

$$
\mathbb{E}_{n^{\prime}, m^{\prime}}\left[\max \left\{P_{t+1}^{e, O}\left(0, n^{\prime}, m^{\prime}\right), P_{t+1}^{e, O}\left(0, n^{\prime}, m\right)\right\}\right]=\mathbb{E}_{n^{\prime}, m^{\prime}}\left[P_{t+1}^{e, O}\left(0, n^{\prime}, \max \left\{m^{\prime}, m\right\}\right)\right] .
$$


Delinquency If an individual decides to be delinquent, her consumption today depends on the labor market choice. In case of delinquency, the individual will suffer a utility loss today of $\psi_{D}<\psi_{B}$. Delinquency in general is advantageous compared with bankruptcy in terms of today's utility because (i) the individual does not pay the resource cost associated with bankruptcy $\left(\Delta_{0}\right.$ or $\left.\Delta_{1}\right)$ and (ii) the utility cost is smaller. Delinquency, in turn, is the worst option in terms of the obligations it imposes on the individual in the future: starting the next period with debt $h$ (we defer a detailed description of this for now). As a result, the functional equations are

$$
D_{t}^{e, O}(b, n, m)=\max \left\{D_{t}^{e, U}(b, n ; 0) ; D_{t}^{e, J}(b, n, m)\right\} .
$$

The individual who rejects the job offer receives the value function described above. The value of choosing delinquency for an individual who accepts a job offer is given by

$$
\begin{aligned}
D_{t}^{e, J}(b, n, m) & =v(c, 1)-\psi_{D}+ \\
& \beta \delta^{e} \mathbb{E}_{n^{\prime}}\left[\max \left\{B_{t+1}^{e, U}\left(n^{\prime} ; 1\right), D_{t+1}^{e, U}\left(b, n^{\prime} ; 1,0\right), P_{t+1}^{e, U}\left(h^{\prime}, n^{\prime} ; 1\right)\right\}\right]+ \\
& \beta\left(1-\delta^{e}\right)\left(1-\lambda^{e, J}\right) \mathbb{E}_{n^{\prime}}\left[\max \left\{B_{t+1}^{e, O}\left(n^{\prime}, m\right), D_{t+1}^{e, O}\left(b, n^{\prime}, m\right), P_{t+1}^{e, O}\left(h^{\prime}, n^{\prime}, m\right)\right\}\right]+ \\
& \beta\left(1-\delta^{e}\right) \lambda^{e, J} \mathbb{E}_{n^{\prime}, m^{\prime}}\left[\max \left\{B_{t+1}^{e, O}\left(n^{\prime}, m^{*}\right), D_{t+1}^{e, O}\left(b, n^{\prime}, m^{*}\right), P_{t+1}^{e, O}\left(h^{\prime}, n^{\prime}, m^{*}\right)\right\}\right]
\end{aligned}
$$

subject to $c=y_{t}^{e}(n, m)+T\left(y_{t}^{e}(n, m)\right)$

$$
m^{*}=\max \left\{m^{\prime}, m\right\} \text {, and } h^{\prime}=\gamma_{t}^{e, J}(b, n, m) \text {, for } t \in[\underline{t}, \bar{t}-2] .
$$

Repayment Lastly, if the borrower decides to repay, they will be able to borrow again. In particular, the individual will issue a one-period bond with face value $b^{\prime}$ and market price $q$. This bond price (characterized below) considers the risk of future bankruptcy and 
delinquency and thus depends on the size of $b^{\prime}$. The functional equations are

$$
P_{t}^{e, O}(b, n, m)=\max \left\{P_{t}^{e, U}(b, n ; 0) ; P_{t}^{e, J}(b, n, m)\right\} .
$$

Recall that $P_{t}^{e, U}(b, n ; 0)$, the value of repaying and rejecting a job offer (which deprives the agent of eligibility for UI) was described above. The value for an individual accepting the job offer is

$$
\begin{aligned}
P_{t}^{e, J}(n, m) & =\max _{b^{\prime}} v(c, 1)+\beta \delta^{e} \mathbb{E}_{n^{\prime}}\left[\max \left\{B_{t+1}^{e, U}\left(n^{\prime} ; 1\right), D_{t+1}^{e, U}\left(b^{\prime}, n^{\prime} ; 1\right), P_{t+1}^{e, U}\left(b^{\prime}, n^{\prime} ; 1,0\right)\right\}\right]+ \\
& \beta\left(1-\delta^{e}\right)\left(1-\lambda^{e, J}\right) \mathbb{E}_{n^{\prime}}\left[\max \left\{B_{t+1}^{e, O}\left(n^{\prime}, m\right), D_{t+1}^{e, O}\left(b^{\prime}, n^{\prime}, m\right), P_{t+1}^{e, O}\left(b^{\prime}, n^{\prime}, m\right)\right\}\right]+ \\
& \beta\left(1-\delta^{e}\right) \lambda^{e, J} \mathbb{E}_{n^{\prime}, m^{\prime}}\left[\max \left\{B_{t+1}^{e, O}\left(n^{\prime}, m^{*}\right), D_{t+1}^{e, O}\left(b^{\prime}, n^{\prime}, m^{*}\right), P_{t+1}^{e, O}\left(b^{\prime}, n^{\prime}, m^{*}\right)\right\}\right],
\end{aligned}
$$

subject to $c=y_{t}^{e}(n, m)+T\left(y_{t}^{e}(n, m)\right)+b-b^{\prime} q_{t}^{e, J}\left(b^{\prime}, n, m\right)$, for $t \in[\underline{t}, \bar{t}-2], m^{*}=\max \left\{m^{\prime}, m\right\}$.

\subsubsection{Individuals Retired}

Finally, retirees have a simpler problem since they face no risk. They still must choose bankruptcy, delinquency, or solvency. If the individual chooses to file bankruptcy, her lifetime utility is

$$
B_{t}^{e, R}(y)=v(c, 0)-\psi_{B}+\beta P_{t+1}^{e, R}(0, n),
$$

subject to $c=g(y)-\Delta_{0}$, for $t \in[\bar{t}, \overline{\bar{t}}-1]$. 
In the case of delinquency, the value is

$$
\begin{aligned}
D_{t}^{e, R}(b, y) & =v(c, 0)-\psi_{D}+\beta \max \left\{B_{t}^{e, R}(y), D_{t}^{e, R}(b, y), P_{t}^{e, R}\left(h^{\prime}, y\right)\right\}, \\
\text { subject to } c & =g(y), h^{\prime}=\gamma_{t}^{e, R}(b, y), \text { for } t \in[\bar{t}, \overline{\bar{t}}-1] .
\end{aligned}
$$

Finally, in the case of repayment, the value function is

$$
P_{t}^{e, R}(y)=\max _{b^{\prime}} v(c, 0)+\beta \max \left\{B_{t}^{e, R}(y), D_{t}^{e, R}\left(b^{\prime}, y\right), P_{t}^{e, R}\left(b^{\prime}, y\right)\right\},
$$

subject to $c=g(y)+b-b^{\prime} q_{t}^{e, R}\left(b^{\prime}, y\right)$, for $t \in[\bar{t}, \overline{\bar{t}}-1]$.

\subsection{Loan Pricing}

Loan prices must satisfy the condition that lenders make zero expected profits. There is a proportional lending cost $\phi$ and a risk-free rate that the lender must recover. In addition, there are costs associated with electing to delay or deny repayment. Consider now a debt issuance of size $b^{\prime}$, which is a promise to repay $b^{\prime}$ units of the consumption good one period hence. Of course, the borrower can invoke bankruptcy, in which case the lender receives nothing (and the borrower incurs the costs and penalties associated with bankruptcy), or initiate the renegotiation process associated with delinquency, the outcome of which is represented by amount $h^{\prime}$. In the latter case, the lender continues to have a claim on the borrower's resources. However, this claim pays nothing in the period in which the delinquency is invoked but, nonetheless, is still worth something: It is the expected present value of the reset amount, $h^{\prime}$, which, given the pricing function $q(\cdot)$, is simply $q h^{\prime}$. We describe in the next section two alternative specifications for $h^{\prime}$.

Let $I_{P}^{e, l}$ be a policy function that takes the value 1 if the individual with education $e$ 
and labor market status $l$ chooses to repay and 0 otherwise. Similarly, let $I_{D}^{e, l}$ be a policy function that takes the value 1 if the individual chooses delinquency and 0 otherwise. Now consider the case of an individual with education $e$ who is currently unemployed, has asked for debt with a face value of $b^{\prime}$ due tomorrow and has current productivity $n$. One period ahead, this loan will be worth (per unit of face value $\left.b^{\prime}\right) q$.

Equilibrium loan prices (expressed per unit of face value on a debt issuance of size $b^{\prime}$ ) must earn zero expected profits for $t \in[\underline{t}, \bar{t}-2]$. For an unemployed agent, expected repayment is given by the right-hand side (RHS) of the following equation:

$$
\begin{aligned}
q_{t}^{e, U}\left(b^{\prime}, n\right) & =\frac{1-\lambda^{e, U}}{1+r+\phi} \mathbb{E}_{n^{\prime}}\left[I_{P, t+1}^{e, U}\left(b^{\prime}, n^{\prime} ; 0\right)+I_{D, t+1}^{e, U}\left(b^{\prime}, n^{\prime} ; 0\right) \frac{h_{1}^{\prime}}{b^{\prime}} q_{t+1}^{e, U}\left(h_{1}^{\prime}, n^{\prime}, b^{\prime}\right)\right]+ \\
& \frac{\lambda^{e, U}}{1+r+\phi} \mathbb{E}_{n^{\prime}, m^{\prime}}\left[I_{P, t+1}^{e, O}\left(b^{\prime}, n^{\prime}, m^{\prime}\right)+I_{D, t+1}^{e, O}\left(b^{\prime}, n^{\prime}, m^{\prime}\right) \frac{h_{2}^{\prime}}{b^{\prime}} q_{t+1}^{e, O}\left(h_{2}^{\prime}, n^{\prime}, m^{\prime}, b^{\prime}\right)\right], \text { where } \\
h_{1}^{\prime} & =\gamma_{t+1}^{e, U}\left(b^{\prime}, n^{\prime} ; 0, d^{\prime}\right), h_{2}^{\prime}=\gamma_{t+1}^{e, O}\left(b^{\prime}, n^{\prime}, m^{\prime}\right) .
\end{aligned}
$$

The first bracketed term describes the expected revenue for the lender if the individual may fail to receive a job offer (with probability $1-\lambda^{e, U}$ ). The second term describes revenue for the case in which the individual receives a job offer with match quality $m^{\prime}$.

Next, we describe loan pricing for an employed agent. In this case, the individual can take one of three paths: transition to unemployment with probability $\delta^{e}$, remain employed at the same job (probability $\left.\left(1-\delta^{e}\right)\left(1-\lambda^{e, J}\right)\right)$, or transition to a new job (probability $\left.\left(1-\delta^{e}\right) \lambda^{e, J}\right)$. 
Thus, the pricing function in this case is

$$
\begin{aligned}
q_{t}^{e, J}\left(b^{\prime}, n, m\right) & =\frac{\delta^{e}}{1+r+\phi} \mathbb{E}_{n^{\prime}}\left[I_{P, t+1}^{e, U}\left(b^{\prime}, n^{\prime} ; 1\right)+I_{D, t+1}^{e, U}\left(b^{\prime}, n^{\prime} ; 1\right) \frac{h_{1}^{\prime}}{b^{\prime}} q_{t+1}^{e, U}\left(h_{1}^{\prime}, n^{\prime}, b^{\prime} ; 1\right)\right]+ \\
& \frac{\left(1-\delta^{e}\right)\left(1-\lambda^{e, J}\right)}{1+r+\phi} \mathbb{E}_{n^{\prime}}\left[I_{P, t+1}^{e, O}\left(b^{\prime}, n^{\prime}, m\right)+I_{D, t+1}^{e, O}\left(b^{\prime}, n^{\prime}, m\right) \frac{h_{2}^{\prime}}{b^{\prime}} t_{t+1}^{e, O}\left(h_{2}^{\prime}, n^{\prime}, m, b^{\prime}\right)\right]+ \\
& \frac{\left(1-\delta^{e}\right) \lambda^{e, J}}{1+r+\phi} \mathbb{E}_{n^{\prime}, m^{\prime}}\left[I_{P, t+1}^{e, O}\left(b^{\prime}, n^{\prime}, m^{*}\right)+I_{D, t+1}^{e, O}\left(b^{\prime}, n^{\prime}, m^{*}\right) \frac{h_{3}^{\prime}}{b^{\prime}} q_{t+1}^{e, O}\left(h_{3}^{\prime}, n^{\prime}, m^{*}, b^{\prime}\right)\right],
\end{aligned}
$$

where $m^{*}=\max \left\{m^{\prime}, m\right\}, h_{1}^{\prime}=\gamma_{t+1}^{e, U}\left(b^{\prime}, n^{\prime} ; 1\right), h_{2}^{\prime}=\gamma_{t+1}^{e, O}\left(b^{\prime}, n^{\prime}, m\right), h_{3}^{\prime}=\gamma_{t+1}^{e, O}\left(b^{\prime}, n^{\prime}, m^{*}\right)$.

For brevity, we omitted the prices that apply since the period before retirement. ${ }^{18}$

\subsection{Delinquency: Determination of the Penalty Rate}

How is $h^{\prime}$ determined? So far, we have not specified how debt in delinquency is reset; we simply used a generic function $\gamma$. Note that the new debt is $h^{\prime}$ and the old debt is $b$. Thus, it is natural to define the gross penalty rate $R^{P} \equiv h^{\prime} / b$. Next, we explore two polar possibilities to determine this rate and a mixture of those two alternatives.

Constant penalty rate The simplest specification we are aware of would build on previous work by Livshits et al. (2007). In this case, delinquency mechanically increases debt by a given penalty rate - that is, $h=b\left(1+\bar{r}^{P}\right)$. We call this specification the "penalty rate" model, as it is motivated by notionally observed practice: Credit card contracts in particular, routinely carry a so-called penalty rate to be charged in the event of delinquency or other failure to pay as promised. In the specific case of the penalty-rate model, however, the value of $h$ is, by construction, entirely independent of the delinquent borrowers characteristics. Of course, it would ideal to more explicitly model lenders choice over this rate instead of setting

\footnotetext{
${ }^{18}$ Since there is no income risk, they are very simple.
} 
it as a parameter. However, for the analysis here, which does not involve computing any counterfactuals but simply evaluating how far this specification can go in reproducing the data, we believe that it is useful - and not misleading - to simply take the observed rate as given.

Resetting penalty rates The second possibility is motivated by the following fact: If the lender lacks commitment, when delinquency occurs the lender can choose any penalty rate whatsoever. ${ }^{19}$ In this case, what is the optimal penalty rate? A forward-looking lender will choose the present-value-maximizing value of the revised debt obligation - that is, the rate that maximizes the market value of debt,

$$
h^{\prime}=\gamma(\cdot)=\arg \max _{x}\{|x q(x, \cdot)|\}
$$

Note that here the function $\gamma$ will be a function of any variables that affects the function q. This assumption seems a very natural candidate for describing credit card markets. The market discipline will be applied ex ante: Since borrowers are forward looking, they can anticipate the penalty rate they will be charged, so they will choose delinquency only if that rate is preferable to the rate available in the marketplace.

Notice that the implicit gross penalty rate charged in delinquency must remain smaller than the rate the market would charge to roll over the outstanding debt. If the borrower chooses to rollover the debt in the marketplace, she must find a value of $\widetilde{b}$ such that $\widetilde{b} q(\widetilde{b}, \cdot)=$ $b$. If such a value does not exist, it means that the market is not willing to rollover $b$ for this borrower. We interpret this finding as evidence that the incumbent lender charges a lower

\footnotetext{
${ }^{19}$ As argued before, according to regulation (CARD Act of 2009) this option is available for lenders after 60 days of delinquency, and there is at least anecdotal evidence that some lenders actually follow this strategy.
} 
rate than the market is charging (no price means infinite price). In addition, notice that there may be more than one such $\widetilde{b}$. In this case, we consider the smaller debt (the largest $\widetilde{b})$. For such a value, we define the gross interest rate as $R^{M}=\frac{\widetilde{b}}{b}$. Notice that if an individual prefers delinquency, it must be true that $R^{P}<R^{M}$. Otherwise, the individual would chose to rollover the debt in the market and avoid the nonpecuniary cost of delinquency, $\psi_{D}$. Note, however, that since the individual may not be able to rollover large debts in the market and labor market circumstances are very bad, the interest rate charged in delinquency may be very high. In those cases, the limit to the power of the lender comes from bankruptcy. If $h^{\prime}$ is very large, the individual will simply choose bankruptcy in the next period, giving the lender nothing.

A "mixture" model It is difficult to know decisively how borrowers and lenders interact upon the initiation of delinquency. Therefore, while the preceding two polar cases are useful benchmarks, it is useful to understand whether an "intermediate" model, in which penalties are sometime, but not always, levied, can better account for the facts we have assembled. We therefore proceed by positing that when resetting occurs, it takes places along lines that are "optimal" in the sense described above. Allowing for both consequences as possibilities in the face of delinquency changes the individual borrowers problem as follows: Once delinquency is invoked by the borrower, the lender decides with a fixed probability which of the two paths to follow. While computationally slightly messier, this approach offers a simple way to nest the polar cases of penalty rates and optimal resetting and, conceptually, is a straightforward extension of the cases described above. In particular, it allows us, via the single parameter, $\rho$, a tractable representation of how delinquency is treated in the data. If this specification turns out to be successful at replicating the data, which is the purpose of the analysis here, 
future work is warranted on what makes lenders want to follow this strategy. One possibility is that there are decreasing returns to the production of information needed to evaluate the characteristics of borrowers in delinquency, so lenders may want to evaluate only a share of all delinquent borrowers. ${ }^{20}$

\section{Calibration}

Our model has a large number of parameters and a large state space. To keep the calibration manageable, we take our labor income process (including the disutility of labor) parameters directly from Low et al. (2010); these are presented in Table A1 in the Appendix. We then are left with only eight parameters needing values for each of the three specifications of the terms of delinquency we examine: penalty rate model, resetting model, and mixture model.

First, we turn to the parameters standard in the literature (shown in the top panel of Table 3). The choice of risk aversion coefficient $\sigma=2$ is standard in macroeconomics. The annual risk-free rate, $r$, is set at 0.375 percent quarterly (or 1.5 percent annually), which is also standard. The parameter $\phi$ is set at 3 percent annually to capture the wedge between the interest rate for credit and deposits not accounted for by the risk of default, which is in line with values used in previous work (such as Athreya, 2008). The costs of filing for bankruptcy are directly from U.S. Government Accountability Office data, and depend on the individual's labor status; this dependence is a simple stand-in for the waivability of filing costs for cause, as the cost of filing while unemployed is smaller than when employed. ${ }^{21}$

The preceding leaves three structural parameters to be assigned to the two polar-case

\footnotetext{
${ }^{20}$ Decreasing returns to the production of information is common in costly state verification models as in Cole et al. (2016) and Greenwood et al. (2010, 2013). In those models, the costly state verification probability is endogenous and determined by incentives to misrepresent and the cost of producing information.

${ }^{21}$ See, e.g., U.S.-Government-Accountability-Office (2008).
} 
Table 3: Key parameters

\begin{tabular}{lcccc}
\hline \hline & & \multicolumn{3}{c}{ Models } \\
Parameter & & Resetting & Penalty Rate & Mixture \\
\hline Risk aversion & $\sigma$ & 2.00 & 2.00 & 2.00 \\
Risk-free interest rate & $r$ & $0.375 \%$ & $0.375 \%$ & 0.375 \\
Transaction cost & $\phi$ & $0.75 \%$ & $0.75 \%$ & 0.75 \\
BK filing fee for $p=1$ & $\Delta$ & $\$ 1200$ & $\$ 1200$ & $\$ 1200$ \\
BK filing fee for $p=0$ & $\Delta$ & $\$ 600$ & $\$ 600$ & $\$ 600$ \\
Penalty rate (yearly, \%) & $R^{P}$ & - & $25 \%$ & $25 \%$ \\
\hline Discount factor & $\beta$ & 0.957 & 0.938 & 0.955 \\
Nonpecuniary cost BK & $\psi_{B}$ & 1.786 & 0.859 & 1.817 \\
Nonpecuniary cost DQ & $\psi_{D}$ & 0.104 & 0.000 & 0.131 \\
Resetting probability & $\rho$ & - & - & 0.405 \\
\hline \hline
\end{tabular}

Note: BK, bankruptcy; DQ, delinquency.

models: the scalar nonpecuniary delinquency cost, $\psi_{D}$, the nonpecuniary bankruptcy cost, $\psi_{B}$, and the discount factor, $\beta$. We determine the value of these parameters to match the three aggregate moments presented in Table 3: the bankruptcy rate, delinquent debt, and mean debt-to-income ratio. We chose these three moments because we can measure them well and because they force the model to account for the incidences of bankruptcy, delinquency, and indebtedness. For example, we chose to target the proportion of debt that is delinquent rather than the overall delinquency rate because, as noted earlier, individuals with several credit cards often are delinquent on only one but nonetheless figure in the calculation of the delinquency rate, as the latter is based on the number of delinquent accounts. While our delinquent-debt measure can capture the phenomenon by taking into account only the amount of debt in delinquency, with the delinquency-rate measure forces us to count an individual as either delinquent or not delinquent.

Although the calibration of the three parameters is jointly executed, there is a close relationship between the following parameters and targets: (i) the discount factor and the 
debt-to-income ratio, (ii) the utility cost of delinquency and the share of delinquent debt, and (iii) the utility cost of bankruptcy and the bankruptcy rate. The hardest parameters to interpret in Table 3 are the utility costs of delinquency and bankruptcy. Their values can be analyzed relative to changes in income, however. The reduction of utility in the period of bankruptcy, $\psi_{B}$, is about 1.8 in the models with resetting. That value is equivalent to about a 65 percent one-period reduction in consumption from the mean consumption. This cost is less than half of that for the pure penalty-rate model. Those numbers may appear large, but recall that borrower can eliminate their entire debt in bankruptcy, so in some situations bankruptcy may still be the best option. The calibrated reduction of utility in the delinquency period is much smaller. We note also that in the pure penalty-rate model, the utility cost is zero is set a the lower bound we considered. Actually, this points to the largest calibration failure among the fit of targets presented in the top panel of Table 4. Since the penalty rate of $25 \%$ is enough to discourage individuals from being delinquent, delinquent debt is too small. To improve along that dimension, the calibration allows for an inflated amount of debt overall relative to the target, so the final calibration of this model also exaggerates the amount of debt. This result is arguably a first sign that, in reality, not all borrowers in delinquency are charged the penalty rates written in their contracts, and importantly, may not expect to be-something that will affect their decision making ex-ante. In contrast, the cases that allow for the resetting of debts after delinquency (second and fourth columns in Table 4) do well in terms of the targeted moments; these models only fall slightly short in generating enough delinquency. ${ }^{22}$

\footnotetext{
${ }^{22}$ Since our model is quarterly, delinquency in our model, strictly speaking, is at least 90 days delinquent. In the data, we observe individuals that are delinquent 30 or 60 days. We decided to include in the targeted delinquency moment individuals that are 60 days delinquent as delinquent because they look more similar to individuals in delinquency than to individuals current in terms of debt payments. The rate of delinquency that counts individuals that are at least 90 days delinquent is smaller and it is, therefore, closer to the number generated by the model.
} 
Table 4: Fit of aggregate moments, 2007

\begin{tabular}{lcccc}
\hline \hline Statistics & Data & \multicolumn{3}{c}{ Models } \\
Targeted: & & Resetting & Penalty rate & Mixture \\
Bankruptcy rate & $1.18 \%$ & $1.01 \%$ & $1.01 \%$ & $1.02 \%$ \\
Delinquent debt & $9.19 \%$ & $7.88 \%$ & $2.22 \%$ & $8.39 \%$ \\
Mean debt/mean income & $1.64 \%$ & $1.51 \%$ & $4.67 \%$ & $1.36 \%$ \\
\hline Non-Targeted: & & & & \\
Bankrupt debt & $2.74 \%$ & $2.62 \%$ & $0.91 \%$ & $2.70 \%$ \\
Delinquency rate & $9.27 \%$ & $0.95 \%$ & $0.33 \%$ & $1.03 \%$ \\
Mean interest rates & $13.7 \%$ & $6.19 \%$ & $7.69 \%$ & $11.1 \%$ \\
\hline \hline
\end{tabular}

The mixture model has an extra parameter, which we denote $\rho$, which specifies the probability for how likely it is that a delinquent borrower will receive a penalty rate or be subject to resetting. We calibrate this parameter to match the change in debt between quarter $t$ and $t+1$ for borrowers delinquent in quarter $t$, which was report in Figure 6 . A mixture model offers a natural way to reconcile theory with data in this dimension. That value we obtained, $\rho=0.405$, indicates that although in most of the cases $(59.5 \%$ of cases) lenders impose the preset "penalty rate" most unsecured credit contracts, they frequently (40.5\% of cases) reset the terms for delinquent borrowers, typically involving partial debt forgiveness.

We next compare the models' predictions about the share of debt discharged in bankruptcy, the delinquency rate, and the mean interest rate, presented in the bottom panel of Table 4. The models with resetting predict bankrupt debt well, fall short predicting the delinquency rate and the mean interest rate, although the latter is much closer. The inability to reproduce the delinquency rate may have to do with, as mentioned above, some individuals in the data being delinquent in only some accounts while in the model that is not allowed (i.e., delinquency in the model is more severe than in the data). This poor result may also 
have to do with the fact that the model does not feature time-varying nonpecuniary costs of default and/or medical expenditure shocks (see the discussion in Athreya et al., 2012) ${ }^{23}$ In general, we note that the class of models studied here usually has problems generating high enough interest rates.

We now turn to the key question posed at the outset: Which of these two models does a better job at helping understand the two facts regarding the dynamics of the persistence of delinquency and its implications for borrowers? In particular, which model best reproduces the (non-targeted) statistics that we presented in Section 2?

\section{Can We Account for the "New"Facts?}

In this section, we focus on the predictions of the models presented and calibrated above, for both the cross-sectional facts, and the facts we documented on the dynamics of default. The purpose of this section is to identify which model is better able to endogenously reproduce important moments that were not targeted during the calibration. Specifically, in each of the polar cases we study-the pure resetting and the pure penalty-rate models-none of the statistics reported in this section were used when calibrating the models. It is only for the case where we allow for both forms of borrower treatment in delinquency described above to operate, i.e., the mixture model, that we let the data guide the choice of the single additional parameter - the probability of having delinquent debt reset as opposed to being treated according to a purely punitive interest rate. Specifically, the probability of facing debt resetting is calibrated to match the distribution of changes in debt among delinquent borrowers.

\footnotetext{
${ }^{23}$ This failure is also common in the sovereign default literature; see Arellano (2008) for a discussion.
} 


\subsection{Debt, Delinquency, and Bankruptcy by Age and Income}

The top panel of Figure 7 shows that all three models reproduce well the path of formal bankruptcy over the lifecycle, especially gives that most borrowers in bankruptcy are 25 to 34 years old. In terms of the fit for delinquency, the middle panel of the same figure shows that the models have very different predictions. While the data show a relatively flat path over the lifecycle, the models with resetting have a decreasing share of debt in delinquency by age, while the penalty-rate model has an increasing share and implies a counterfactually high share of delinquent debt among the oldest working borrowers. The main reason for the latter is the calibration of the discount factor. As we mentioned above, since the high penalty rate discourages agents from choosing delinquency, the calibration of that model returns a lower discount factor and zero nonpecuniary cost of delinquency. In turn, this calibration leads to more debt and delinquency among the old.

The preceding raises a more general fact about comparing outcomes across the various models: Recalibrating each case makes comparisons difficult but is necessary given our goal of identifying the model most capable of matching the dynamics of debt and default we focus on. 
Figure 7: Debt, Delinquency, and Bankruptcy by age group
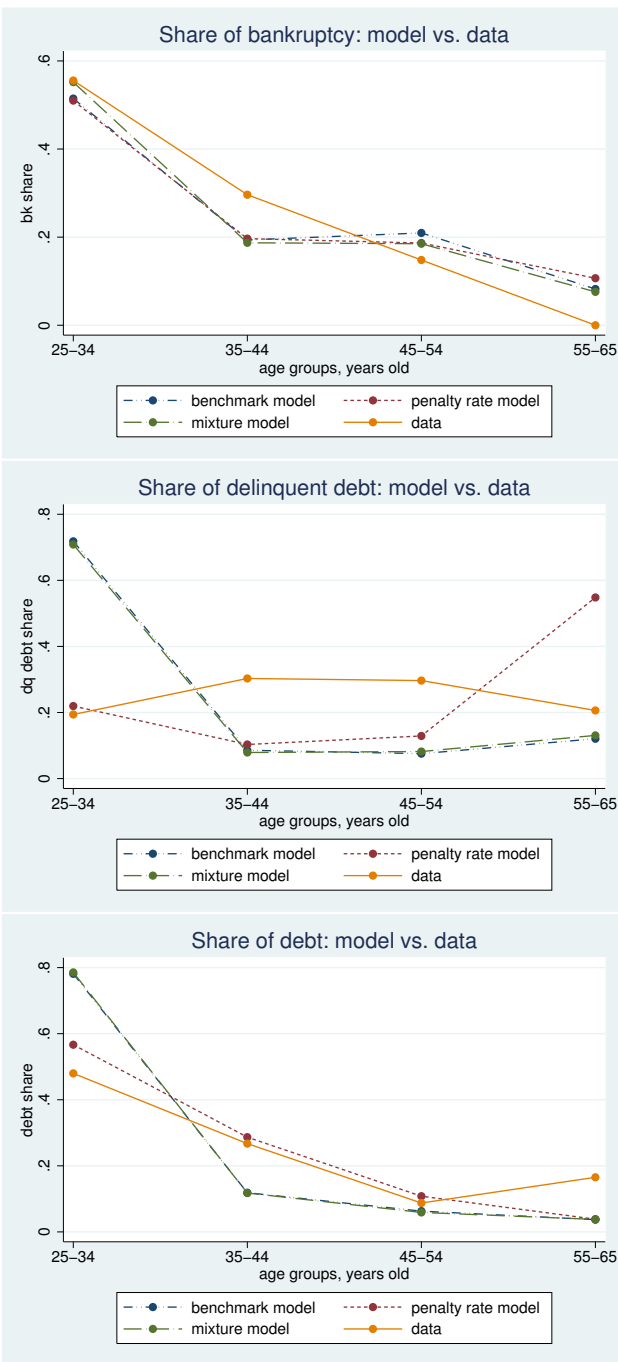

Source: See Appendix.

Notice next that in the data most of the debt is held by younger borrowers, a fact well reproduced by the three models, especially the penalty-rate model. The hump-shaped lifecycle profile of income essentially ensures this and shows that there are strong intertemporal motives to borrow, and with the low unconditional probability of default (delinquency or 
bankruptcy), the presence or absence of penalties or debt relief does not strongly influence the use of debt.

Figure 8 shows the distribution by income quartiles. As shown in the top panel, in the three models and in the data, most bankruptcies are filed by borrowers in the bottom income quartile, although the models have a steeper profile than the data. This result again is a natural consequence of borrowing being concentrated among the young, with their incomes also being lower on average than older agents, and default being useful for borrowers suffering misfortune. In this sense, default does appear to be playing a role, at least ex-post, in smoothing consumption across states of nature. The two bottom panels show that the models with resetting better replicate the delinquent share of debt (middle panel) and the share of debt overall (bottom panel) across income quartiles. With respect to delinquent debt shares, we see that all three models are too steep for the share of debt in delinquency and too flat for the share of debt. In particular, the pure penalty-rate model does not lead to as much debt among the lowest income quartile (as seen in the bottom panel of Figure 8). The model faces the problem that the calibration requires the model to, like other models, capture the overall level of delinquent debt. Notice that these same agents will, due to the life-cycle profile, also be disproportionately young. This then leads to a profile that overstates the share of delinquent borrowers with higher incomes (typically older individuals) in the pure penalty-rate model. 
Figure 8: Debt, Delinquency, and Bankruptcy by income quartile
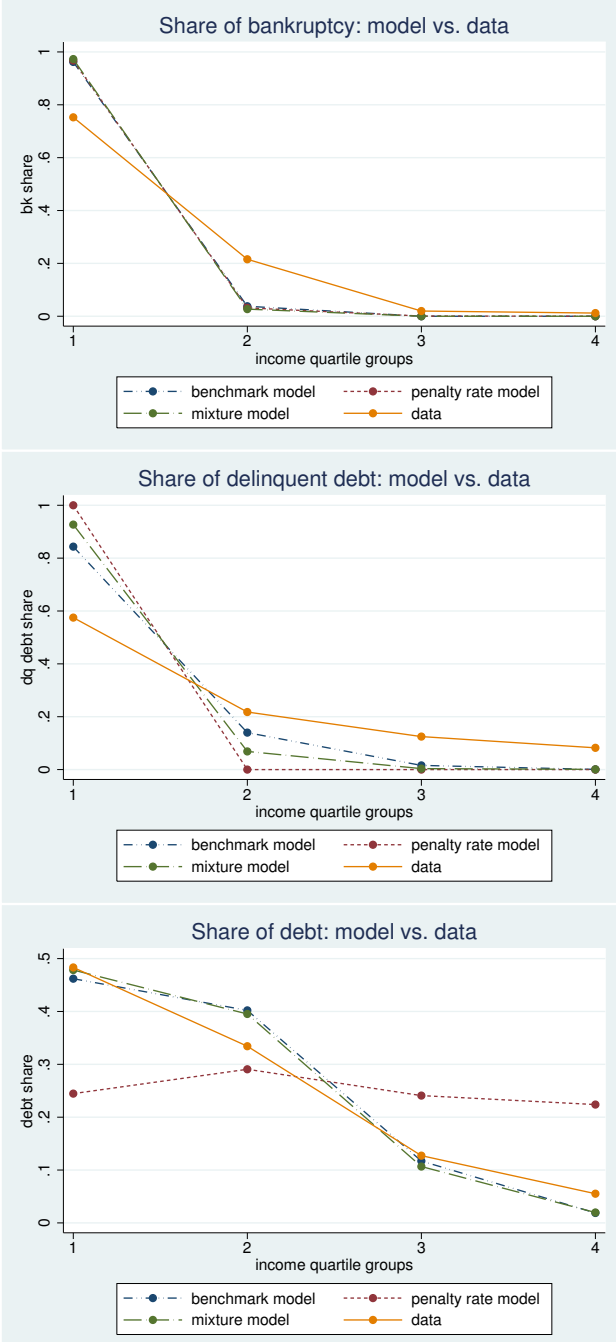

Source: See Appendix

\subsection{The Dynamics of Default}

We turn now to the question that most directly motivated us: Can we understand the dynamics of consumer debt delinquency? To understand the models' implications relative 
to the data for measures of the persistence of financial conditions, we begin with Table 5 . This table shows how the alternative models reproduce the transitions in credit status. For exposition, we omit one category because the three categories add up to one. There are two salient features in the data: (i) It is very rare for borrowers to go directly into bankruptcy without first being delinquent, and (ii) The cessation of payments is not that persistentonly about 14 percent of the borrowers in delinquency for the first time (DQ1) in a given quarter stop making payments the following quarter.

How well can the models replicate the data? All the models overestimate the transition probability from current to bankruptcy. However, in the models with resetting (columns 3 and 5), the transition probability from current to bankruptcy is significantly lower than that from current to delinquency, as in the data. Thus, the models with resetting replicate the first salient feature of the data, although quantitatively not as extreme as observed in the data. The pure penalty-rate model, however, fails to replicate this feature: A borrower making payments on time in period $t$ is twice more likely to file for bankruptcy than be delinquent in period $t+1$, because she prefers to avoid the high penalty rate.

The second important fact is that in the data, the cessation of payment is transitory (one quarter) for $85 \%$ of the borrowers $(100 \%-14 \%-1 \%)$, while in the pure penalty-rate model it is transitory only for $57 \%$ of borrowers. This is the case simply because it is very hard to make payments with such a high penalty rate. Moreover, for the same reason, the penalty rate model has a transition probability from being "60 or 90 days delinquent" to bankruptcy that is ten times higher than in the data. For this transition probability, the model with pure resetting is significantly better: the cessation of payment is transitory for about $90 \%$ of the borrowers, much closer to $85 \%$ than the pure penalty-rate model. In the mixture model, about 37 percent of the borrowers in delinquency for the first time in a given quarter will 
Table 5: Persistence of financial distress

\begin{tabular}{lcccc}
\hline \hline Probabilities & Data & \multicolumn{3}{c}{ Models } \\
& & Resetting & Penalty rate & Mixture \\
\hline Current at $\mathrm{t} \&$ BK at $\mathrm{t}+1$ & $0.05 \%$ & $0.24 \%$ & $0.22 \%$ & $0.21 \%$ \\
Current at $\mathrm{t} \&$ DQ at $\mathrm{t}+1$ & $1.38 \%$ & $0.75 \%$ & $0.11 \%$ & $0.50 \%$ \\
\hline DQ1 at t \& BK at t+1 & $0.96 \%$ & $1.45 \%$ & $9.75 \%$ & $6.54 \%$ \\
DQ1 at t \& DQ2 at t+1 & $14.0 \%$ & $8.18 \%$ & $33.6 \%$ & $37.2 \%$ \\
\hline \hline
\end{tabular}

Note: See Appendix.

not make any payments until the next quarter. This feature is the main failure of this model and arises from the high interest rate imposed on borrowers in delinquency. ${ }^{24}$

The final evaluation of the models is performed using the change in debt for borrowers in delinquency. The most salient fact in the data is that there is a large dispersion in the changes. Although the majority of the changes are positive, almost 40 percent of the changes are negative. The pure penalty-rate model fails by construction, since in this model the change is the same and equal to the penalty rate for all the borrowers in delinquency (top panel of Figure 9). In the model with pure resetting, this change is endogenous and selected by lenders. The results for that case are presented in the middle panel of Figure 9. That model puts too much mass on negative changes. The relative performance of the models under consideration are given in Figure 9. The comparison of the top and middle panels suggests that a mixture of the two models may be reasonable, whereby lenders use both methods with positive probability. The predictions of the mixture model are given in the bottom panel. The superiority of the mixture model relative to the two polar-case models along this dimension of the data should perhaps not be surprising. However, what

\footnotetext{
${ }^{24}$ One may wonder why this transition probability is higher for the mixture model than the pure penaltyrate model. We think this is related to the calibration of the mixture model. Note that the pure penalty-rate model largely underestimate the share of people and debt in delinquency, while the mixture model does a fairly good job at replicating the targets in Table 4. Thus, it is not surprising that the mixture model presents a higher persistence of delinquency than the pure penalty-rate model.
} 
is surprising is that extending the analysis simply to allow for a mixture of the two previous models in this probabilistic manner yields a fit to the entire distribution of debt changes that is as good as seen here.

Figure 9: Debt change for households in DQ
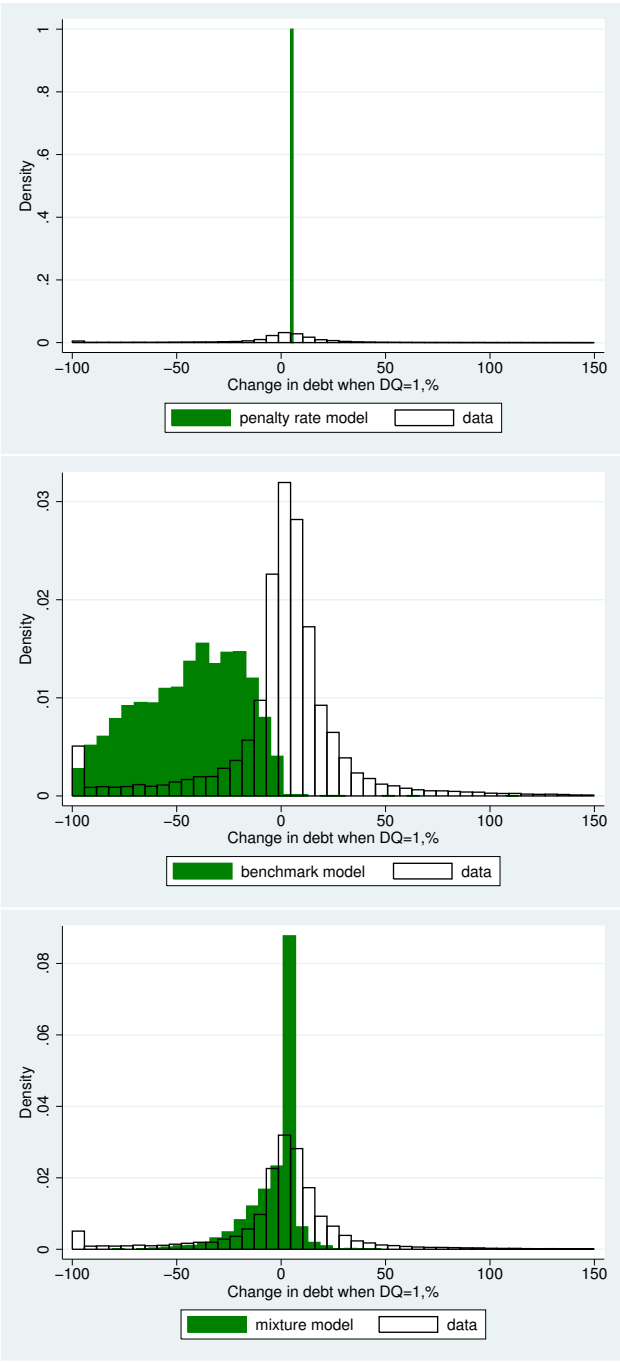

Source: See Appendix.

Overall, we view the results as strongly suggestive that, in practice, delinquent borrower 
does not automatic face a penalty rate, but rather a significant amount of renegotiation. It is this mixture model that allows us to account reasonably, though certainly not fully, for a variety of empirics around consumer debt and delinquency. In particular, we are able to report relative success in simultaneously understanding both borrower transitions to and from delinquency and the empirical distribution of changes to borrower debt conditional on delinquency.

\section{Conclusions}

Unsecured debt default, especially by informal means, is frequent. However, the credit terms borrowers subsequently face are very difficult, if not impossible, to directly observe. What is observable, however, is how debt evolves among those currently delinquent, and the transitions between bankruptcy, delinquency, and being current on payments. Among the facts we uncover, two are especially salient: (i) The cessation of payments for debt in delinquency is typically transitory in nature, and (ii) Borrowers in delinquency routinely reduce their debt. In this paper, we first use a large, and to our knowledge, comprehensive, set of panel and cross-sectional data sources to provide a rich body of cross-sectional and panel facts. We then demonstrate that these facts provide useful discipline on rich structural models. We proceed to identify which model, within the class of models we consider, is most capable of accounting for borrower debt, delinquency, and bankruptcy.

Our findings suggest that purely punitive behavior by creditors, while consistent with casual empiricism on unsecured credit contracts, fail to explain the data. Instead, our analysis suggests a strong role for an alternative consequence, in our model represented by the optimal resetting of debt, that routinely yields the reductions in debt observed in the 
data. Our findings arise from a model that we have argued presents a useful account of the workings of the unsecured credit market by incorporating important institutional features of the consumer credit market. 


\section{A Appendices}

\section{A.1 Data appendix}

These appendices provide a description of the data sets used. All statistics are calculated for borrowers aged 25 to 65 except for the data from the Board of Governors of the Federal Reserve System and the Administrative Office of the U.S. Courts.

\section{A.1.1 Aggregate Statistics}

Bankruptcy (BK) rate. BK rate uses Survey of Consumer Finances (SCF) data. The dummy variable, $I_{B K}$, has value 1 if one files for bankruptcy one year before the survey year, i.e., $X 6772=1$ and $X 6773=1$. The BK rate is calculated as:

$$
\mathrm{BK} \text { rate }=\frac{\sum_{i=1}^{N} I_{B K_{i}}}{N},
$$

where $N$ denotes the total population.

Bankrupt debt. BK debt uses data from the Board of Governors of the Federal Reserve System (charge-off rate of consumer loans in the fourth quarter for each year, all banks, seasonally adjusted). Since this aggregate statistic is directly retrieved from the Federal Reserve Board of Governors' web site, we cannot perform age restriction in this case.

Delinquency (DQ) rate. DQ rate is calculated using data from Federal Reserve Bank of New York Consumer Credit Panel/Equifax. A dummy variable $I_{D Q}$ is defined for each individual. $I_{D Q}=1$ if the individual is more than 60 days delinquent but not bankrupt (60 DPD, 90 DPD, 120 DPD or Severe Derogatory) - that is, crtr_attr35 > 0, or crtr_attr36 > 0, 
or crtr_attr37 $>0$, or crtr_attr38 $>0$, and crtr_attr39 $=0$. Then the DQ rate is calculated as

$$
\text { DQ rate }=\frac{\sum_{i=1}^{N} I_{D Q_{i}}}{N} .
$$

Delinquent debt. DQ debt is also calculated using data from Federal Reserve Bank of New York Consumer Credit Panel/Equifax. Debt is measured by the variable crtr_attr169, total bankcard balance excluding bankruptcy. DQ_debt is measured by the sum of balances of all delinquent accounts if an individual is more than 60 days delinquent but not bankrupt, i.e., DQ_debt $=$ crtr_attr109 + crtr_attr110 + crtr_attr111 + crtr_attr112. Thus, our measure is

$$
\text { DQ debt }=\frac{\sum_{i=1}^{N} I_{D Q_{i}} \cdot \text { DQ_debt }_{i}}{\sum_{i=1}^{N} \operatorname{Debt}_{i}} .
$$

Mean debt/Mean income. The ratio of mean debt to mean income is calculated using data from SCF. Debt is defined as the larger value of zero and the negative of net worth; i.e.,

$$
\mathrm{DEBT}=\max \{0,-\mathrm{NETWORTH}\}
$$

Income refers to total income. Thus, our measure is

$$
\frac{\text { Mean debt }}{\text { Mean income }}=\frac{\sum_{i=1}^{N} \mathrm{DEBT}_{i}}{\sum_{i=1}^{N} \mathrm{INCOME}_{i}} .
$$

Mean Interest Rates. Mean interest rate uses SCF data. The interest rate is measured by the variable $X 7132$. The average is calculated only for the borrower who reports a positive interest rate; i.e., $X 7132>0$. 


\section{A.1.2 Statistics by Age Groups}

Define dummies for the four age groups; i.e., $I_{\text {age }_{k}}$, where $k \in\{1,2,3,4\}$ and borrowers aged

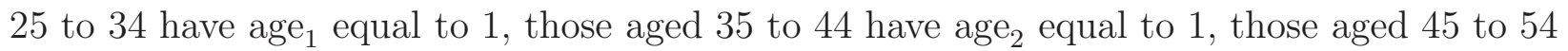

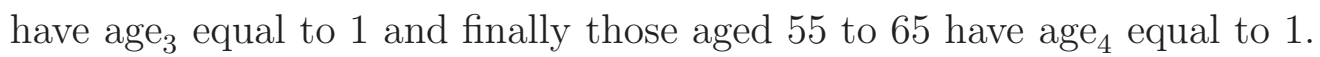

Share of bankruptcy. BK rate by age group is calculated using data from PSID 2007. Age is measured by the variable ER10009 (age of head of household), and the dummy variable $I_{B K}$ equals 1 if $Q 32 J 25 F=1$; i.e., the borrower has filed for or taken bankruptcy (as a result of economic problems in the last 12 months).

$$
\text { Share of BK for age group } k=\frac{\sum_{i=1}^{N} I_{B K_{i}} \cdot I_{\text {age }_{i, k}}}{\sum_{i=1}^{N} I_{B K_{i}}} \text {. }
$$

Share of delinquent debt. Share of DQ debt by age groups uses data from Federal Reserve Bank of New York Consumer Credit Panel/Equifax. Both debt and delinquent debt are defined as above.

$$
\text { Share of DQ debt for age group } k=\frac{\sum_{i=1}^{N} \mathrm{DQ}_{-} \mathrm{debt}_{i} \cdot I_{\mathrm{age}_{i, k}}}{\sum_{i=1}^{N} I_{D Q_{i}} \cdot \mathrm{Debt}_{i}} \text {. }
$$

Share of debt. Share of debt by age groups uses SCF. Debt is defined above.

$$
\text { Share of debt for age group } k=\frac{\sum_{i=1}^{N} \mathrm{DEBT}_{i} \cdot I_{\mathrm{age}_{i, k}}}{\sum_{i=1}^{N} \mathrm{DEBT}_{i}} \text {. }
$$

\section{A.1.3 Statistics by Income Group}

Define dummies for the four income groups; i.e., $I_{\text {income }_{k}}$, where $k \in\{1,2,3,4\}$ and borrowers with income are in the bottom 25 th percentile have income ${ }_{1}$ equal to 1 , those between 
the 25 th and 50 th percentiles have income 2 equal to 1 , those between the 50 th and 75 th percentiles have income 3 equal to 1 , and finally those above the 75 th percentile have income 4 equal to 1 .

Share of bankruptcy. BK rate by income groups uses 2008 data from the Administrative Office of the U.S. Courts (all individuals in the data filed for bankruptcy in 2007). Income percentiles are calculated using 2007 SCF total income data.

$$
\text { Share of BK for income group } k=\frac{\sum_{i=1}^{N} I_{B K_{i}} \cdot I_{\text {income }_{i, k}}}{\sum_{i=1}^{N} I_{B K_{i}}} \text {. }
$$

Share of delinquent debt. Share of DQ debt by income group uses data from Federal Reserve Bank of New York Consumer Credit Panel/Equifax matched with CRISM data. The two data sets are matched for the same period using the variable CID. Income refers to the variable PIM (personal income model estimation) in CRISM.

$$
\text { Share of DQ debt for income group } k=\frac{\sum_{i=1}^{N} \mathrm{DQ}_{-} \mathrm{debt}_{i} \cdot I_{\text {income }_{i, k}}}{\sum_{i=1}^{N} I_{D Q_{i}} \cdot \operatorname{Debt}_{i}} \text {. }
$$

Share of debt. Share of debt by income groups uses SCF. Income and debt are defined as above.

$$
\text { Share of debt for income group } k=\frac{\sum_{i=1}^{N} \mathrm{DEBT}_{i} \cdot I_{\text {income }_{i, k}}}{\sum_{i=1}^{N} \mathrm{DEBT}_{i}}
$$

\section{A.1.4 Transition Probabilities}

Transition probabilities are calculated using data for the first and second quarters of each year from Federal Reserve Bank of New York Consumer Credit Panel/Equifax. 
Current at $t$ and DQ at $t+1$. Take the borrowers with all the accounts current in quarter $t$ and compute the share of those with at least one 60-day or more delinquent account in quarter $t+1$, i.e., including 60 DPD, 90 DPD, 120 DPD and Severe Derogatory.

Current at $t$ and BK at $t+1$. Take the borrowers with all accounts current in quarter $t$ and compute the share of those with at least one account in bankruptcy in quarter $t+1$.

Current at $t$ and current at $t+1$. This is the residual transition. Take the borrowers with all accounts current in quarter $t$ and compute the share of those with all accounts current or 30 days delinquent in quarter $t+1$.

DQ1 at $t$ and making no payments at $t+1$. Take the borrowers with at least one $X$-day delinquent account (60 or 90 days late) and compute the share of those with at least one $X+90$ day delinquent account. In this case, if the borrower is 60 (90) days delinquent in quarter $t$, then he is counted as making no payments if he is severe derogatory in quarter $t+1$.

DQ1 at $t$ and BK at $t+1$. Take the borrowers with at least one delinquent account (60 or 90 days late) and compute the share of those with at least account in bankruptcy in quarter $t+1$.

DQ1 at $\mathbf{t}$ and making payments at $t+1$. This is calculated as the residual transition. Take the borrowers with at least one delinquent account (60 or 90 days late) and compute the share of those who have made some payments (current, 30 DPD, 60 DPD, 90 DPD, or 120 DPD in quarter $t$ ). 


\section{A.1.5 Changes in debt}

Change in debt is calculated as $100 *\left[\left(\frac{\text { Total debt }_{t+1}}{\text { Total debt }_{t}}\right)-1\right]$ for borrowers who have $D Q 1=1$ in quarter t, using data for the first and second quarter of each year in Federal Reserve Bank of New York Consumer Credit Panel/Equifax. DQ1 at period $t$ is defined as 60 DPD or 90 DPD.

\section{A.2 Other Parameters for the Income Process}

Table A1: Parameters from Low et al. (2010)

\begin{tabular}{|c|c|c|c|}
\hline & & High Ed. & Low Ed. \\
\hline Education distribution & $\Upsilon$ & 0.568 & 0.432 \\
\hline Std. deviation of permanent shock & $\sigma_{\zeta}$ & 0.106 & 0.095 \\
\hline Std. deviation of firm-worker shock & $\sigma_{m}$ & 0.229 & 0.226 \\
\hline Job separation rate & $\delta$ & 0.022 & 0.039 \\
\hline Job arrival rate in unemployment & $\lambda^{N}$ & 0.709 & 0.657 \\
\hline Job arrival rate in employment & $\lambda^{E}$ & 0.623 & 0.579 \\
\hline Fixed cost of work & $F$ & $\$ 1,213$ & $\$ 1,088$ \\
\hline Disutility of working & $\varphi$ & -0.620 & -0.550 \\
\hline Total hours of work & $h$ & 500 & 500 \\
\hline UI replacement ratio & $\vartheta$ & 0.750 & 0.750 \\
\hline UI cap & $\Xi$ & $\$ 2,384$ & $\$ 2,384$ \\
\hline DI application successful rate & $s$ & 0.500 & 0.500 \\
\hline Maximum food stamp & $\Gamma$ & $\$ 800$ & $\$ 800$ \\
\hline Food stamp threshold & $\underline{Y}$ & $\$ 2831$ & $\$ 2831$ \\
\hline DI threshold 1 & $a_{1}$ & $\$ 1,203$ & $\$ 1,203$ \\
\hline DI threshold 2 & $a_{2}$ & $\$ 7,260$ & $\$ 7,260$ \\
\hline DI threshold 3 & $a_{3}$ & $\$ 16,638$ & $\$ 16,638$ \\
\hline
\end{tabular}

Note: DI, disability insurance; UI, unemployment insurance; Ed, education. 


\section{References}

ADP-Research-Institute, "ADP Research Institute Study Offers First In-Depth Look at Garnishment Rates Among U.S. Workers," 2014 Press Releases, September 2014.

Agarwal, S. AND C. Liu, "Determinants of credit card delinquency and bankruptcy: Macroeconomic factors," Journal of Economics and Finance 27 (March 2003), 75-84.

Arellano, C., "Default Risk and Income Fluctuations in Emerging Economies," American Economic Review 98 (June 2008), 690-712.

Athreya, K., "Default, Insurance, and Debt over the Life-Cycle," Journal of Monetary Economics 55 (May 2008), 752-774.

Athreya, K., J. M. SÁnchez, X. S. Tam and E. R. Young, "Labor Market Upheaval, Default Regulations, and Consumer Debt," Review of Economic Dynamics 18 (January 2015), 32-52.

Athreya, K., X. S. Tam And E. R. Young, "A Quantitative Theory of Information and Unsecured Credit," American Economic Journal: Macroeconomics 4 (July 2012), 153-83.

Benjamin, D. And X. Mateos-Planas, "Formal versus Informal Default Consumer Credit," Working Paper, October 2014.

Chatterjee, S., "An Equilibrium Model of the Timing of Bankruptcy Filings," Unpublished manustript, June 2010.

Chatterjee, S., D. Corbae, M. Nakajima and J.-V. Ríos-Rull, "A Quantitative Theory of Unsecured Consumer Credit with Risk of Default," Econometrica 75 (June 2007), 1525-1591. 
Chatterjee, S. And G. Gordon, "Dealing with consumer default: Bankruptcy vs garnishment," Journal of Monetary Economics 59 (December 2012), 1-16.

Cole, H. L., J. Greenwood and J. M. Sanchez, "Why Doesn't Technology Flow From Rich to Poor Countries?," Econometrica 84 (07 2016), 1477-1521.

EARL, D., The Bankruptians (Exposition Press, 1966).

FTC, "The Structure and Practices of the Debt Buying Industry," Technical Report, Federal Trade Commission, 2013.

Fulford, S. L., "How important is variability in consumer credit limits?," Journal of Monetary Economics 72 (2015), 42-63.

Greenwood, J., J. Sanchez and C. Wang, "Quantifying the Impact of Financial Development on Economic Development," Review of Economic Dynamics 16 (January 2013), $194-215$.

Greenwood, J., J. M. Sanchez and C. Wang, "Financing Development: The Role of Information Costs," American Economic Review 100 (September 2010), 1875-91.

Halpern, J., Bad Paper: Chasing Debt from Wall Street to the Underworld (Farrar, Straus and Giroux, 2014).

Herkenhoff, K. F. and L. E. Ohanian, "Foreclosure Delay and U.S. Unemployment," Working Paper, March 2012.

JacoB, H., Debtors in Court: The Consumption of Government Services (Rand McNally and Co, 1969). 
Kovrijnykh, N. and B. Szentes, "Equilibrium Default Cycles," Journal of Political Economy 115 (June 2007), 403-446.

Lehnert, A. And D. M. Maki, "Consumption, Debt and Portfolio Choice: Testing the Effect of Bankruptcy Law," Working Paper, 2002.

Livshits, I. And N. Kovrijnykh, "Screening as a Unified Theory of Delinquency, Renegotiation, and Bankruptcy," 2015 Meeting Papers 1401, Society for Economic Dynamics, 2015.

Livshits, I., J. MacGee and M. Tertilt, "Consumer Bankruptcy: A Fresh Start," American Economic Review 97 (March 2007), 402-18.

Low, H., C. Meghir and L. Pistaferri, "Wage Risk and Employment Risk over Life Cycle," American Economic Review 100 (September 2010), 1432-67.

Pew-Charitable-Trusts, "Two steps forward: After the Credit CARD Act, Credit Cards Are Safer and More Transparent-But Challenges Remain," Technical Report, The Pew Charitable Trusts, 2010.

Simon, J. M., "Bank of America stops disclosing default APRs," Blog post, CreditCards.com, 2010.

Sullivan, T. A., E. Warren and J. L. Westbrook, The Fragile Middle Class: Americans in Debt (Yale University Press, 2000).

Telyukova, I. And R. Wright, "A Model of Money and Credit, with Application to the Credit Card Debt Puzzle," Review of Economic Studies 75 (2008), 629-47. 
U.S.-Government-Accountability-Office, "Dollar Costs Associated with the Bankruptcy Abuse Prevention and Consumer Protection Act of 2005," Report to Congressional Requesters, June 2008. 